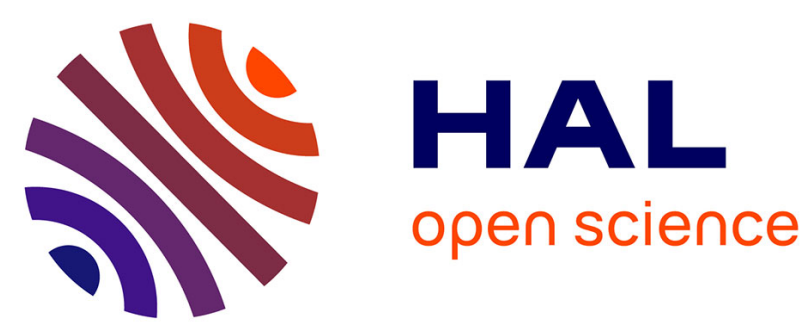

\title{
La tombe de Coste Rouge à Beaufort (Hérault) et la question des tombes à dalles néolithiques dans le nord-est des Pyrénées
}

Jean Vaquer, Henri Duday, Muriel Gandelin, Stéphane Hérouin, Anne Tresset

\section{- To cite this version:}

Jean Vaquer, Henri Duday, Muriel Gandelin, Stéphane Hérouin, Anne Tresset. La tombe de Coste Rouge à Beaufort (Hérault) et la question des tombes à dalles néolithiques dans le nord-est des Pyrénées. Gallia Préhistoire - Archéologie de la France préhistorique, 2007, 49, pp.127-159. 10.3406/galip.2007.2453 . hal-02345871

\section{HAL Id: hal-02345871 \\ https://hal.science/hal-02345871}

Submitted on 16 Jan 2020

HAL is a multi-disciplinary open access archive for the deposit and dissemination of scientific research documents, whether they are published or not. The documents may come from teaching and research institutions in France or abroad, or from public or private research centers.
L'archive ouverte pluridisciplinaire HAL, est destinée au dépôt et à la diffusion de documents scientifiques de niveau recherche, publiés ou non, émanant des établissements d'enseignement et de recherche français ou étrangers, des laboratoires publics ou privés.

\section{(ㅇ)(1) $\$$}

Distributed under a Creative Commons Attribution - NonCommercial - NoDerivatives| 4.0 


\title{
LA TOMBE DE COSTE ROUGE À BEAUFORT (HÉRAULT) ET LA QUESTION DES TOMBES À DALLES NÉOLITHIQUES DANS LE NORD-EST DES PYRÉNÉES
}

\author{
Jean VAQUER*, Henri DUDAY**, Muriel GANDELIN*, \\ Stéphane HÉrouin**, Anne TreSSET ${ }^{* * *}$
}

\begin{abstract}
Mots-clés. Languedoc, Chasséen, tombe à dalles enfouie, inhumation, mobilier funéraire, pointe à pédoncule et ailerons, Dentalium, dépôt symbolique de restes de faune.

Résumé. La tombe de Coste Rouge est une structure funéraire submégalithique établie dans une fosse qui se rapporte à un type connu aussi bien au Néolithique moyen (groupe pyrénéen de Solsona ou groupe périalpin de Chamblandes) qu'au Chalcolithique et au Bronze ancien. Bien qu'endommagée par un charruage, son architecture a pu être restituée, ce qui a permis de noter que la dernière dalle mise en place n'est pas la couverture, comme c'est le cas dans les coffres ou les cistes, mais celle du petit coté sud-est et que cette dernière était précédée d'un espace dans la fosse d'implantation de la "chambre». Cette structure contenait les restes d'un enfant couché sur le dos. Il portait un ornement à double rang de dentales autour de l'épaule gauche et un lot de pendentifs foliacés façonnés sur des plaquettes osseuses se trouvait près de sa tête. Il disposait aussi d'un équipement constitué de deux lamelles en silex blond bédoulien du Vaucluse, de deux armatures à pédoncule et ailerons en silex et de quatre poinçons en os groupés près de la main gauche. L'architecture et le mobilier révèlent des affinités typologiques avec certains ensembles funéraires catalans de la région de Solsona qui suggèrent de l'attribuer à la fin du Néolithique moyen (Chasséen languedocien), ce qui est confirmé par une datation radiocarbone. Cette tombe a livré un dépôt d'os de faune domestique (bovin, caprinés, canidé) et sauvage (ours, canidé) qui sont intimement liés au dépôt du cadavre et peuvent représenter des amulettes ou constituer l'évocation symbolique d'un bestiaire d'accompagnement.
\end{abstract}

Keywords. Languedoc, Chassean, buried slab tomb, inhumation, grave goods, stemmed and winged point, Dentalium, symbolic deposit of faunal remains.

Abstract. The Coste Rouge tomb is a sub-megalithic funerary structure in a pit of a type known in the Middle Neolithic (Pyrenean group of Solsona or peri-Alpine group of Chamblandes), Chalcholithic and Early Bronze Age. Though damaged by ploughing, we were able to restore its architecture and observe that the last slab put in place was not the cover, as in the case of coffin or cist tombs, but that of the small south-east side, and that this latter was preceded by a space in the pit of the "chamber". This structure contained the remains of a child laid on its back. It was wearing an ornament with two rows of Dentalium shells around its left shoulder and a set of foliate pendants shaped from bone plaques was found near its head. It was also accompanied by two bladelets in Bedoulan blonde flint from the Vaucluse region, two winged and stemmed points, and four bone awls grouped near the left hand. The architecture of the grave goods reveals typological affinities with certain Catalonian funerary ensembles from the Solsona region, suggesting an attribution to the end of the Middle Neolithic (Languedoc Chassean period), which has been confirmed by a radiocarbon date. This tomb yielded a deposit of domestic (bovid, caprids, canid) and wild (bear, canid) faunal remains that are intimately related to the cadaver deposit and could represent amulets or constitute a symbolic representation of an accompanying bestiary.

Translation: Magen O'FARRELL

* UMR 8555 du CNRS : «Centre d’anthropologie », Université Paul-Sabatier, 39 allées Jules-Guesde, F-31000 Toulouse. Courriels : vaquerjean@ aol.com ; gandelin.muriel@gmail.com

** UMR 5199 du CNRS : « Laboratoire d'anthropologie des populations du passé (LAPP) », Université Bordeaux-I, Avenue des Facultés, F-33405 Talence Cedex. Courriels : h.duday@anthropologie.u-bordeaux1.fr ; herouin.stephane@neuf.com

*** UMR 5197 du CNRS : «Archéozoologie et histoire des sociétés humaines », Muséum national d'histoire naturelle, 55 rue Buffon, F-75005 Paris. Courriel : atresset@cimrsl.mnhn.fr 
Palabras clave. Languedoc, Chasséen, sepulcros de fosa revestida de losas, inhumación, ajuar funerario, punta con pedúnculo y aletas, Dentalium, depósito simbólico de restos de fauna.

Resumen. El sepulcro de Coste Rouge es una estructura funeraria sub-megalítica construida dentro de una fosa que se relaciona con un tipo bien conocido tanto en el Neolítico medio (grupo pirenaico de Solsona o grupo peri-alpino de Chamblandes) como en el Calcolítico y el Bronce Antiguo. A pesar de que fue dañada por un labor, se ha podido reconstruir su arquitectura, lo cual ha permitido advertir que la última losa colocada no es la cobertura, como en el caso de las arcas o las cistas, sino la situada ligeramente al sudeste y que estaría precedida de un espacio en la fosa de implantación de la cámara. Dicha estructura contenía los restos de un niño en posición de decúbito supino. Portaba un adorno de dos filas de "Dentalia" alrededor del hombro izquierdo y un conjunto de colgantes foliáceos confeccionados en placas de hueso que se encontró situado cerca del cráneo. Disponía también de un equipo constituido por dos láminas en sílex melado beduliense del Vaucluse, de dos puntas de flecha con pedúnculo y aletas en sílex y de cuatro punzones de hueso agrupados cerca de la mano izquierda. Tanto la arquitectura como el ajuar revelan afinidades tipológicas con algunos conjuntos funerarios catalanes de la región de Solsona, lo que sugiere su atribución al final del Neolítico medio (Chasséen Languedociense), que se confirma por una datación radiocarbónica. Este sepulcro ofrece también la presencia de un depósito de huesos de fauna doméstica (bovinos, caprinos y cánidos) y salvaje (oso, cánido) que están íntimamente ligados a la sepultura y podrían representar sus amuletos o constituir la evocación simbólica de un bestiario de acompañamiento.

Traducción: Marta SANZ TOLEDO

La question des tombes néolithiques «à dalles» est récurrente en Languedoc occidental. Ce type identifié au début du siècle dernier dans l'Aude (Fages, 1923 et 1930) a fait, dans les années 1960, l'objet d'une série de recherches dans le Limouxin (Guilaine, 1962). Les études publiées à ce moment-là ont souligné les affinités entre ces monuments attribués au Chasséen méridional et ceux de la culture catalane des Sepulcros de fosa (Tombes en fosse), notamment ceux de son faciès de Solsona (Guilaine, Muñoz, 1964). C'est à la suite de la fouille d'une nouvelle série de tombes situées à Najac, Siran (Hérault) dans le Minervois, qu'une reprise globale de cette problématique a été tentée à une échelle plus vaste. Bien qu'elle n'ait pas contesté les affinités catalanes pour les tombes en «ciste » ou en «coffre»du Languedoc occidental et du Roussillon, la publication synthétique qui en a résulté a rappelé que ce type de tombe avait une répartition beaucoup plus vaste, puisqu'on le trouve aussi dans le Massif central et surtout dans le domaine périalpin où il peut se manifester dans des contextes plus anciens que le Chasséen (Mahieu, 1992). C'est au même moment, dans la publication consacrée aux monuments de l'aire de Tavertet dans la région d'Osona en Catalogne, que des différences importantes ont été constatées au sein même du groupe de Solsona ; en effet, la plupart des coffres de cet ensemble sont inclus dans de grands tertres circulaires et ont livré du mobilier de type Montbolo (Molist et al., 1987 ; Cruells et al., 1992). Cette configuration a ensuite été confirmée par d'autres ensembles funéraires, notamment à Camp del Ginebre, Caramany (Pyrénées-Orientales) où la nécropole présente d'ailleurs une diversité étonnante de tombes dont des cistes enfouies sous de petits tumulus circu- laires (Vignaud, 1995). Parallèlement, il a pu être démontré que certaines tombes à dalles du groupe de Solsona ne sont pas des cistes ou des coffres mais des « chambres ", car elles peuvent avoir une fermeture frontale et avoir servi pour plusieurs sépultures successives (Castany, 1990 et 1992).

La problématique concernant ces tombes apparaît donc beaucoup plus complexe qu'auparavant et s'inscrit désormais dans le cadre plus global de l'émergence du mégalithisme en domaine méditerranéen (Guilaine, 1996), ou tout au moins du polymorphisme des expressions funéraires au Néolithique moyen dans le midi de la France (Vaquer, 1998). Plus récemment, une nouvelle découverte laisse même penser que ce type de tombe a pu exister au Néolithique récent dans la région (Vignaud, 2000), ce qui tend à contredire la thèse d'une disparition rapide des tombes individuelles à appareillage lithique à la fin du Néolithique moyen. Dans ce contexte en plein changement, la découverte d'une nouvelle tombe de ce type à Coste Rouge, Beaufort (Hérault), nous a paru constituer une belle opportunité pour tenter de renouveler cette question.

\section{LE SITE DE COSTE ROUGE}

Le site de Coste Rouge se trouve au cœur des vignobles du Minervois dans la commune de Beaufort (Hérault). Il correspond au débouché oriental de la combe d'Oupia drainée par le ruisseau de l'Écu, dont le bassin versant couvre le flanc nord de l'anticlinal du Serre d'Oupia. La butte de Coste Rouge, constituée de terrains marno-gréseux appartenant aux molasses de l'Éocène supérieur (formation d'Aigne), domine d'une quarantaine de mètres la plaine 


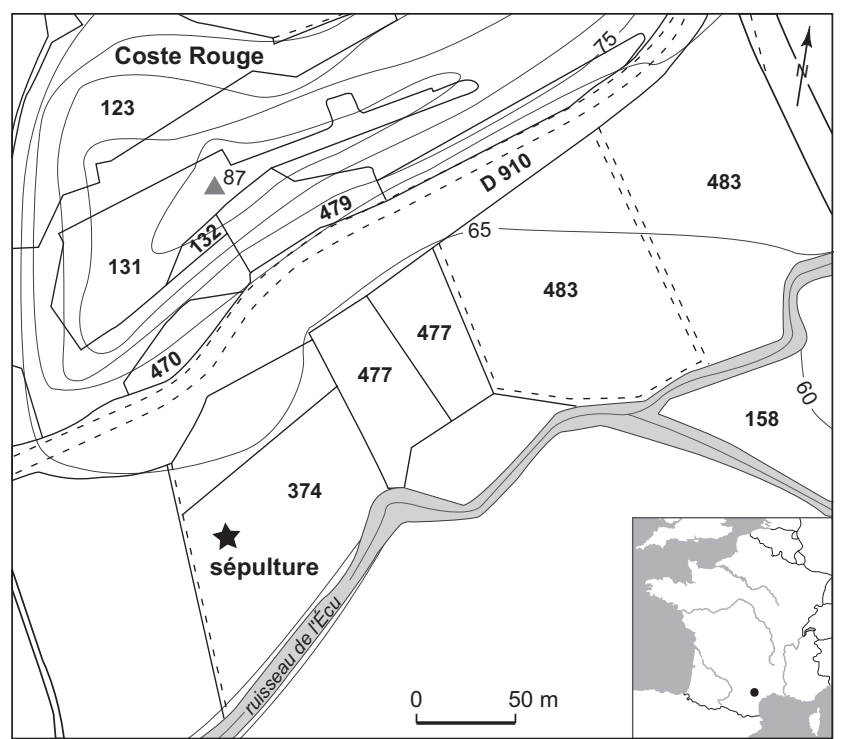

Fig. 1 - Tombe de Coste Rouge à Beaufort (Hérault). Localisation de la sépulture dans la parcelle A 374 (DAO : M. Gandelin).

d'Olonzac formée de colluvions récentes et d'alluvions issues du bassin de l'Aude et de l'Ognon. Le site archéologique de Coste Rouge se trouve au pied de la colline, sur le glacis sud qui la sépare du cours incisé du ruisseau de l'Écu où il occupe la parcelle 374 (fig. 1 et 2). Ce gisement est connu par les archéologues locaux en raison de la découverte ancienne d'une nécropole protohistorique, dite de Coste Rouge, qui a été signalée par M. Louis et O. Taffanel (1958) à partir de mentions plus anciennes (Miquel, 1895 ; Cazalis de Fondouce, 1900).

\section{CIRCONSTANCES DE LA DÉCOUVERTE DE LA TOMBE ET HISTORIQUE DE LA FOUILLE}

C'est en effectuant un défonçage de la parcelle afin de renouveler son vignoble que $\mathrm{M}$. Michel Durand, propriétaire exploitant, souleva une grosse dalle de grès en novembre 2000. Pensant qu'il pouvait s'agir de l'affleurement d'un banc de roche gênant pour la mise en culture, il entreprit un décapage réduit avec un tractopelle qui révéla la présence d'une autre dalle horizontale reposant sur des pierres plantées verticalement formant un coffre. Intrigué par cet agencement, son jeune fils Sylvain creusa à l'intérieur du coffre sur une trentaine de centimètres et mit en évidence la présence d'un crâne humain. Certains d'avoir découvert une tombe ancienne, ils prévinrent Joëlle Granier, archéologue bénévole du Centre de recherche et

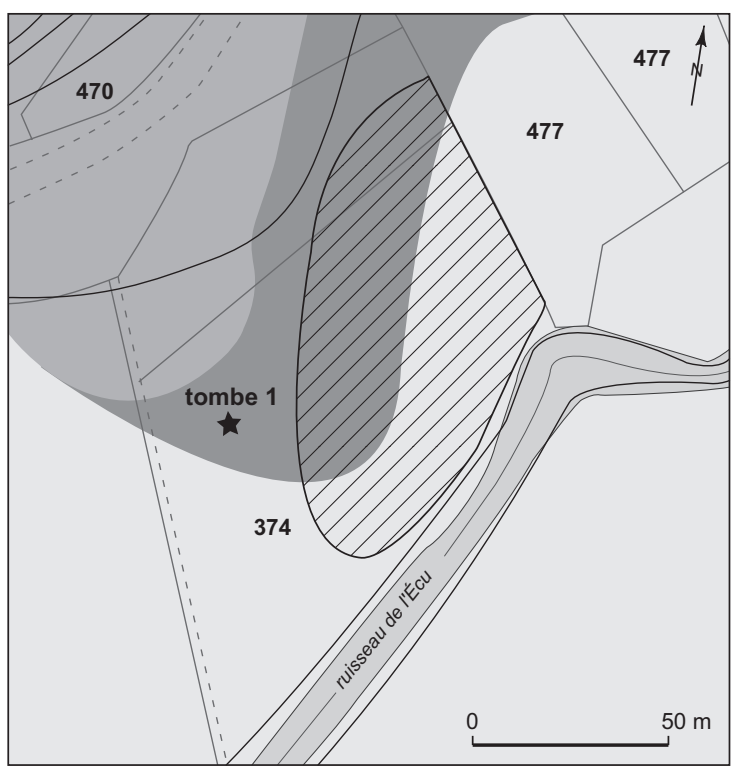

molasse éocène $\square$ colluvions grossières colluvions fines $\square \backslash$ nécropole à incinération (âge du Fer)

Fig. 2 - Tombe de Coste Rouge à Beaufort (Hérault). Topographie et pédologie du site (DAO: M. Gandelin).

de documentation du Minervois, qui authentifia la valeur archéologique de cette découverte et se chargea de la déclarer au Service régional de l'archéologie.

Une expertise de terrain, réalisée par deux agents du service (C. Olive et P.-A. de Labriffe), permit de proposer une datation probablement préhistorique pour cette tombe en coffre. La partie fouillée de la tombe fut alors rebouchée avec de la terre noire prélevée en bordure du champ, en attendant qu'une fouille de sauvetage urgent puisse être réalisée. Dans la mesure où cette tombe en coffre appartient à un type connu au Néolithique qui fait l'objet d'un thème de recherche intitulé «Monuments et rites funéraires préhistoriques dans le midi de la France » au sein du programme du Centre d'anthropologie, cette opération fut proposée à l'un de nous (J. V.) par le conservateur régional de l'archéologie.

En préalable à l'intervention, une prospection de surface a été réalisée sur la parcelle défoncée, ce qui a permis de mieux cerner la configuration du gisement archéologique. Dans la partie nord-ouest de la parcelle, qui est la plus élevée, le labour a atteint la marne rosée ou jaune de l'Éocène qui forme le substratum géologique du site. Dans sa partie ouest, un paléosol constitué de limon sablograveleux de teinte brun orangée se présente à l'affleurement ; c'est dans cette formation que se trouvaient la tombe et une possible fosse à remplissage cendreux, non datée 
(rares restes de faune et un tesson modelé), ainsi que des vestiges épars du Néolithique ou du Chalcolithique (éclats et lamelles en silex blond de style chasséen, éclats de silex locaux, une flèche à pédoncule). La découverte en surface de quelques éléments de parure (un fragment de bracelet en pétoncle, une perle discoïde en stéatite, une perle discoïde en test, une Columbella percée) pourrait témoigner de la présence éventuelle d'autres sépultures néolithiques. Toute la partie est de la parcelle, en contrebas, présente un sol brun limoneux incluant de nombreuses pierres et des restes évidents de sépultures à incinération qui correspondent à la nécropole protohistorique signalée par plusieurs auteurs (Louis et al., 1958). Parmi les vestiges significatifs recueillis en surface, on note quelques éléments métalliques : des fragments de torques à section ronde ou losangique, un fragment de petite enclume en bronze et une tige fine en fer (une épingle ?), ainsi que de nombreux tessons de céramique modelée appartenant à des coupes en calotte, des coupes carénées à bord évasé, des gobelets globuleux décorés de cannelures larges, des fragments d'urnes globuleuses à bord évasé et lèvre incisée, ou d'urnes à col haut, et des fragments d'urnes à fond annulaire. Ces éléments sont identiques à ceux des phases 2 et 3 de la nécropole du Moulin à Mailhac, Aude (Taffanel et al., 1998).

L'intervention sur la tombe néolithique fut dans un premier temps projetée pour le début du mois de mai 2001, date à laquelle le propriétaire devait replanter la vigne. Les difficultés de montage financier de l'opération et de disponibilité de l'équipe nous ont obligés à reporter cette intervention au mois de juin, puis à solliciter une prolongation jusqu'à fin juillet. Entre-temps le propriétaire avait replanté la vigne, sauf dans les deux rangées permettant l'accès au chantier, ce qui a enlevé toute possibilité d'étendre le décapage ou d'effectuer d'autres sondages en vue de préciser si la tombe était isolée ou appartenait à une éventuelle nécropole que rien toutefois ne signale en surface. La fouille proprement dite s'est déroulée du 4 au 18 juillet avec une équipe de huit personnes en moyenne.

\section{STRATÉGIE DE FOUILLE ET MÉTHODE}

Les sépultures à appareillage de dalles, du Néolithique, du Chalcolithique ou des débuts de l'âge du Bronze connues dans le midi de la France ou dans les régions périphériques (Catalogne, Suisse ou Italie), correspondent grosso modo à un groupe qui a pour caractéristique principale un fonctionnement impliquant un accès vertical, généralement obturé après utilisation par une ou plusieurs dalles faisant office de couvercle. En fait, cette définition générale cache une assez grande variabilité et des types architecturaux bien différents. C'est ainsi que l'on distingue parmi celles qui sont incluses dans des fosses, d'une part, des cistes qui sont petites et à sépulture individuelle, comme une grande partie des tombes de type Chamblandes du Néolithique moyen lémanique (Moinat, 1998) ou celles des nécropoles du Bronze ancien-moyen rhodanien et, d'autre part, des coffres, plus grands, à fermeture par le haut mais à sépultures généralement multiples ou successives. D’autres types établis dans des tertres ou à flanc de talus ont été reconnus dans le Néolithique moyen et récent pyrénéen de la région de Solsona (Castany, 1990). Ils présentent un accès frontal et sont alors qualifiés de « chambres » ou de « niches » solsoniennes, pour les différencier des dolmens pyrénéens normalement construits hors sol et recouverts d'un tumulus. Il existe aussi des tombes à fermeture supérieure construites au-dessus du sol et insérées dans des tumulus, c'est le cas des monuments de type Tavertet-Caramany du Néolithique moyen catalan de style Montbolo, ou de ceux du Chasséen, notamment l'exemplaire de Saint-Jean-du-Désert à Marseille (Sauzade, Grenet, 1996). Ces caractéristiques peuvent se retrouver dans certains coffres mégalithiques datés du Chalcolithique ou du Bronze ancien, comme par exemple ceux du piémont nord-pyrénéen tels que le Puey Mayou ou La Halliade de Bartrès (Hautes-Pyrénées).

Outre le type de réceptacle du cadavre, il apparaît donc que la position de la tombe par rapport au niveau de circulation de l'époque et surtout l'existence d'éventuels dispositifs de signalisation ou le recouvrement par un tumulus constituent des paramètres très importants. Ces aspects n'ont que très rarement été pris en compte, y compris dans des fouilles récentes qui n'ont concerné que l'intérieur des espaces sépulcraux. C'est la raison pour laquelle la fouille de la structure de Beaufort ne s'est pas limitée au coffre, mais aussi à ses abords dans la mesure du possible, ce qui a impliqué le nettoyage de toute la surface décapée et la réalisation de coupes dans l'encaissant.

Le second point, encore très mal connu, au sujet de ces types de tombes concerne la structuration des dépôts internes, qu'il s'agisse des restes humains ou des dépôts de mobilier. Ces aspects ont été le plus souvent traités de façon schématique. Bien qu'il s'agisse de sépultures en espace protégé, les conditions de conservation des restes osseux sont rarement optimales dans de telles tombes. Il faut donc faire la part de ce qui découle des conditions naturelles d'enfouissement et de préservation des restes et envisager, le cas échéant, des interventions humaines postérieures au 
dépôt funéraire qui sont rendues possibles par l'existence du coffre (Moinat, 1998). Afin d'aborder ces questions dans les meilleures conditions, la méthode de fouille a consisté à effectuer des décapages optimaux successifs avec des procédures d'enregistrement tridirectionnel graphique, complétées par des enregistrements photographiques argentiques et numériques, puis par un démontage avec enregistrement sur place des paramètres ostéologiques, tels que l'identification et la position de chaque os. Cette méthode a impliqué la mise en place d'un châssis tubulaire démontable permettant une fouille fine sans gêner les prises de vue et l'installation d'un dispositif de protection globale du chantier contre les intempéries, certains décapages devant être laissés en place pendant plus d'une journée. Cette méthode nous a obligés cependant à démonter l'architecture de la tombe pour pouvoir accéder aux niveaux les plus profonds.

\section{LA TOMBE : DONNÉES ARCHITECTURALES}

Toutes les pierres utilisées pour la construction du coffre sont en grès du Tertiaire local qui peut provenir du versant de Coste Rouge, situé à une centaine de mètres à l'ouest du monument. Lors de notre première intervention sur le terrain, nous avons constaté que les dalles verticales du coffre n'étaient que partiellement dégagées dans un environnement de terre probablement remaniée par les labours et les ruissellements. Les dalles de couverture avaient été enlevées, celle qui avait été trouvée lors du défonçage avait été emportée en bordure ouest du champ, l'autre gisait sur le tas de déblais. Quelques autres fragments moins volumineux et parfois cassés de frais se trouvaient sur le tas de déblais; nous les avons mis à part afin de tenter des remontages.

\section{LES DALLES DE COUVERTURE}

Bien qu'elles n'aient pas été observées en place, les dalles de couverture ont fait l'objet de relevés précis afin d'enregistrer leur morphologie ou des traces éventuelles de façonnage, puis de proposer une restitution de leur agencement initial. Celle-ci s'appuie sur les indications des découvreurs et sur des déductions. Il est possible, en effet, de reconnaître leur face supérieure marquée par des coups de charrue et leur face inférieure recouverte d'un encroûtement de calcin, puis de les positionner de façon théorique en fonction de l'orientation des éraflures provoquées par le soc métallique (fig. 3).
La dalle 1, qui recouvrait la partie sud-est du coffre, était cassée de frais à l'un de ses angles, mais elle a pu être reconstituée car un petit fragment trouvé sur le tas de déblais a pu être recollé. Il s'agit d'une dalle subtrapézoïdale avec un petit coté à angle droit et un autre oblique, manifestement épannelé. D’après les informations du propriétaire, il est possible de la replacer sur le coffre car la partie pointue se trouvait vers le sud. Cette dalle, qui mesure 1,36 m de long, $0,75 \mathrm{~m}$ de large et 0,11 $\mathrm{m}$ d'épaisseur, devait peser environ $170 \mathrm{~kg}$ en supposant une densité de ce grès de 2,3.

La dalle 2, trouvée au moment du défonçage, porte des coups de charrue anciens et deux plus récents, dont l'un a entamé un des petits côtés. L'écartement entre ces sillons de soc et leur orientation permet de replacer cette dalle dans la partie nord-ouest du coffre. Elle mesure 1,10 m de long, $0,83 \mathrm{~m}$ de large et $0,16 \mathrm{~m}$ d'épaisseur. Son poids peut être estimé à environ $220 \mathrm{~kg}$.

Une troisième dalle plus petite $(0,68 \mathrm{~m} \times 0,45 \mathrm{~m}$ x $0,5 \mathrm{~m})$, trouvée dans les déblais, a pu compléter la couverture du coffre, soit au niveau de la jonction des deux grosses dalles, soit sur un angle où subsistent quelques vides. Son poids estimé est de l'ordre de $20 \mathrm{~kg}$.

\section{LA FOSSE}

Afin de contrôler dans quel type de structure se trouvait le coffre, toute la zone décapée a été raclée jusqu'au niveau en place. C'est ainsi que l'on a pu retrouver la semelle de labour marquée par des sillons de carrelets dont l'écartement et l'orientation ont permis de restituer l'agencement des dalles de couverture. Il est apparu que le niveau de base du labour contenait vers le sud-est quelques fragments de dalles cassées de frais qui ont pu être recollés sur la dalle oblique qui ferme le coffre au sud-est; cela a permis de retrouver sa hauteur originelle qui dépassait d'une dizaine de centimètres celle des dalles latérales. Quelques éléments (des tessons, une phalange humaine et un fragment de pendeloque en os) ont été trouvés au nord-ouest du coffre ; ils proviennent probablement des déblais du remplissage du coffre rejetés dans ce secteur lors du sondage exploratoire réalisé au moment de la découverte.

Nous avons nettoyé cette surface en place de façon à percevoir les limites d'une éventuelle structure d'implantation qui est restée imperceptible en plan; nous avons donc poursuivi la fouille en réservant des bermes le long des axes longitudinal et transversal afin de détecter les traces, soit d'une fosse, soit d'un éventuel tumulus enfoui. Alors qu'il existait une différence assez nette entre le comblement 


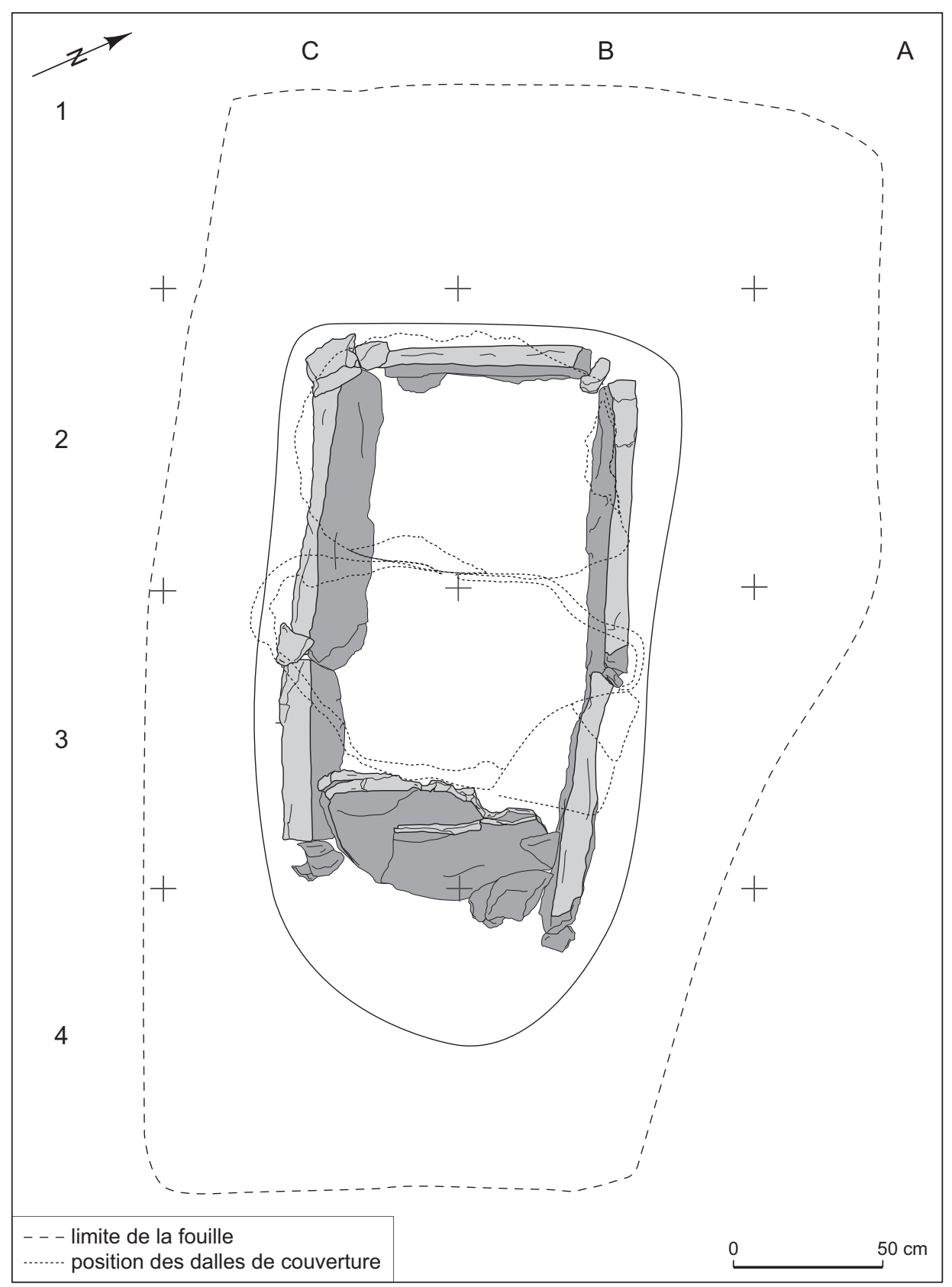

Fig. 3 - Tombe de Coste Rouge à Beaufort (Hérault).

Plan de la zone fouillée : en pointillé, position restituée des dalles de couverture (DAO : M. Gandelin).

de l'intérieur de la tombe, constitué d'un limon brun foncé assez meuble, et le sédiment entourant la structure en dalles, qui est formé d'un limon brun orangé chargé en sable et petits graviers, aucune différence évidente de couleur n'est apparue lors du décapage de la périphérie du coffre. Nous avons dû creuser sur une vingtaine de centimètres autour du coffre, et même plus profondément dans la partie est, pour nous rendre compte qu'il avait été construit au fond d'une fosse.

La délimitation de celle-ci a été essentiellement fondée sur des critères de texture du sédiment et sur le cheminement de nombreuses racines de vigne qui étaient plaquées contre les parois de cette fosse comblée. Un sondage de contrôle réalisé dans l'encaissant au niveau du 


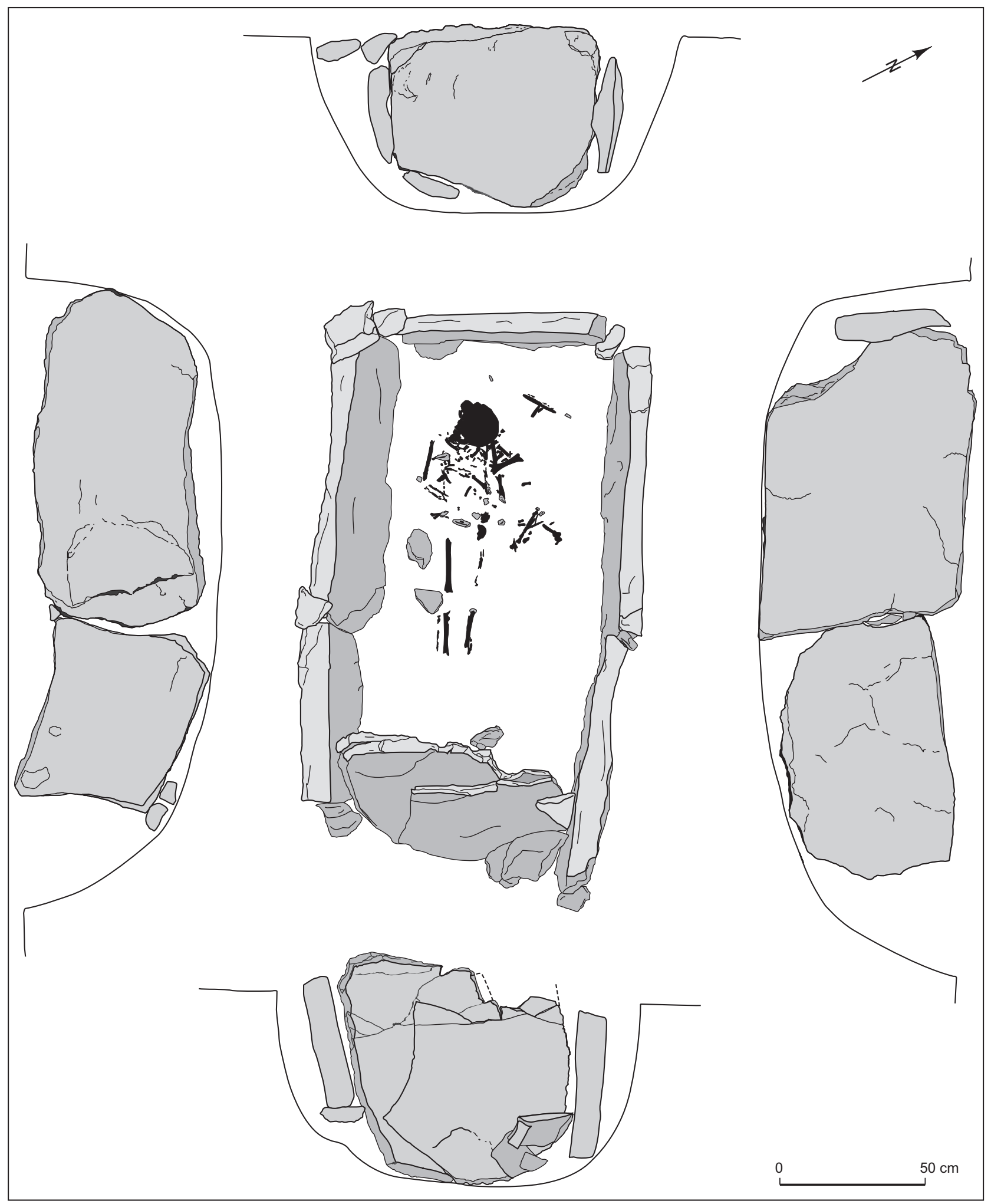

Fig. 4 - Tombe de Coste Rouge à Beaufort (Hérault).

Relevé zénithal et projections latérales des parois lithiques (DAO: M. Gandelin). 


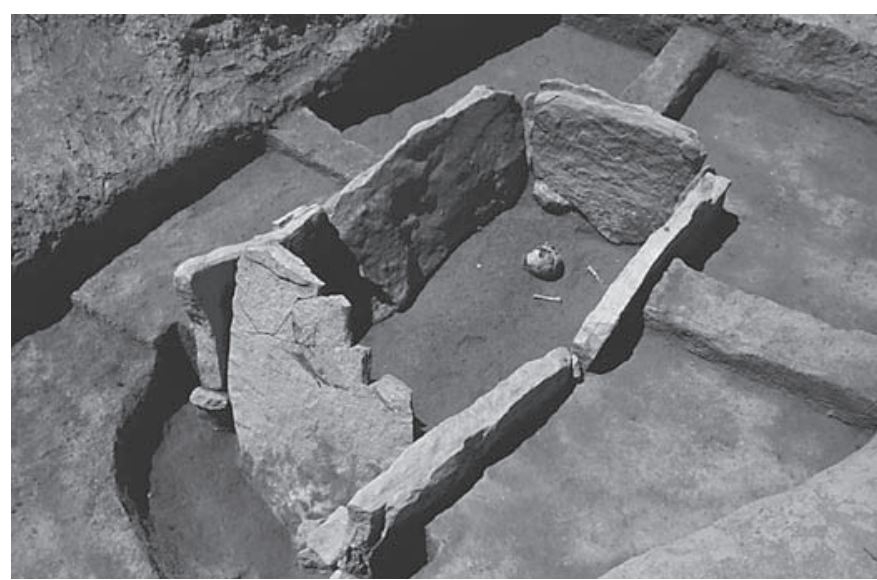

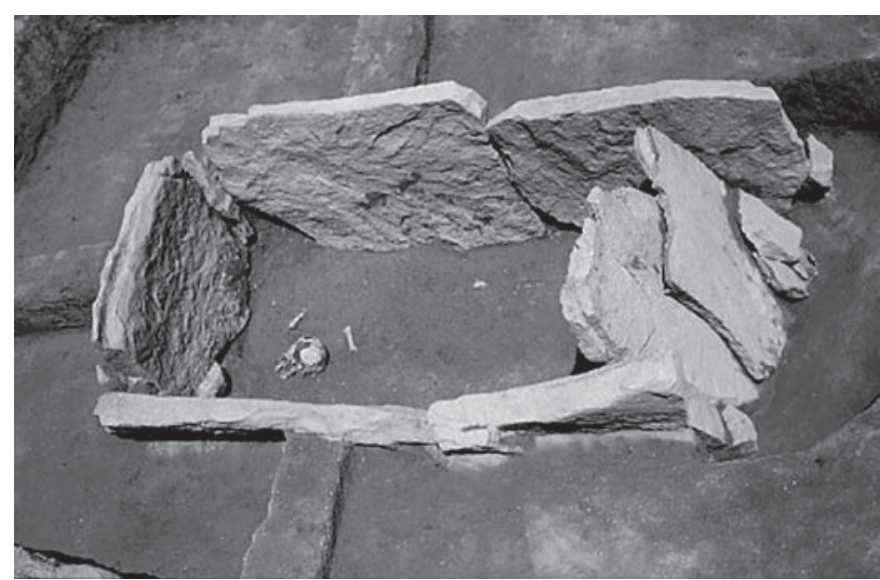

b

Fig. 5 - Tombe de Coste Rouge à Beaufort (Hérault).

Architecture de la tombe : a, vue de l'est ; b, vue du sud (clichés :J. Vaquer, CNRS).

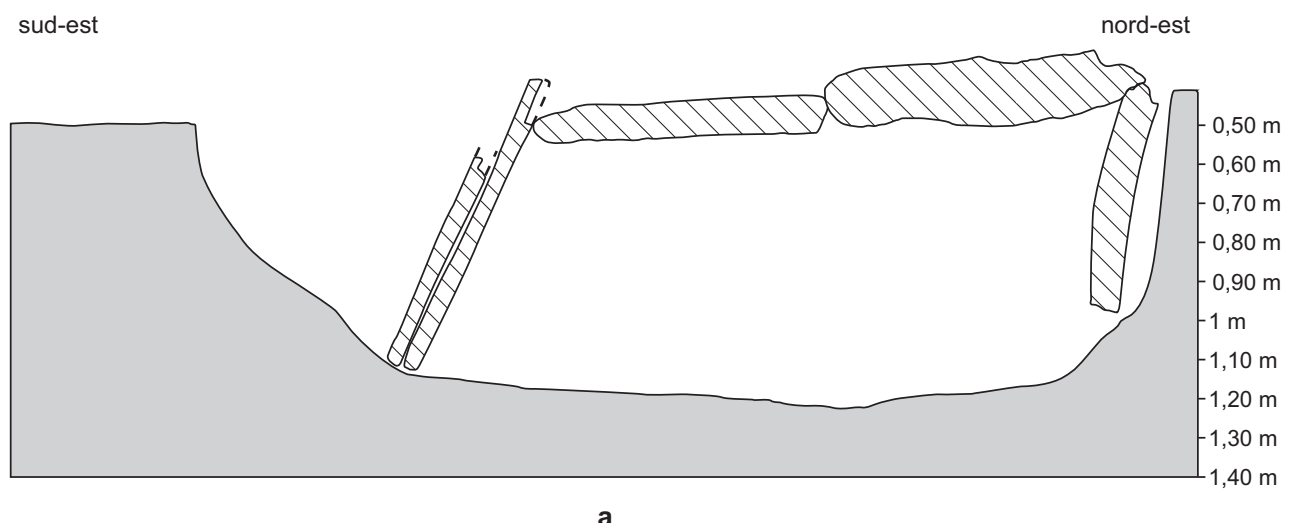

sud-ouest

nord-ouest

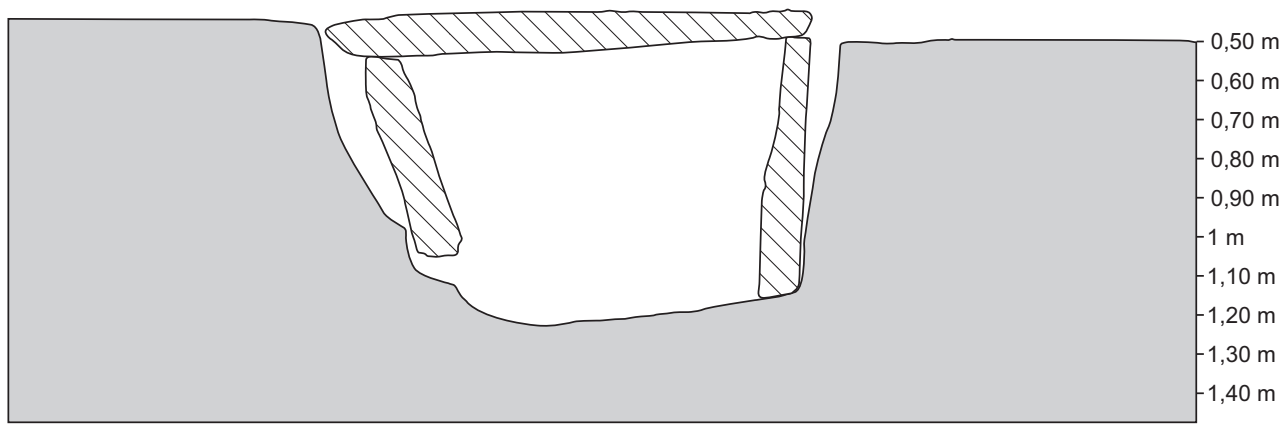

b

Fig. 6 - Tombe de Coste Rouge à Beaufort (Hérault) :

a, coupe longitudinale; $b$, coupe transversale (DAO : M. Gandelin). 
carré B4 a montré que le substratum était constitué par un paléosol comportant une alternance de niveaux limoneux et graveleux subhorizontaux partiellement concrétionnés par du calcin, tandis que le remplissage de la fosse constitué de sédiments similaires ne montrait aucune organisation stratigraphique.

À partir de ces critères, il est possible d'affirmer que la fosse avait un contour subrectangulaire et des parois quasi verticales à très faible distance des orthostates le long des cotés nord-est, sud-ouest et nord-ouest, et qu'elle présentait un dégagement semi-circulaire à paroi inclinée dans la partie sud-est. Cette fosse mesurait 2,40 m de long sur $1,35 \mathrm{~m}$ de large et avait un profil concave avec une gouttière décentrée vers le sud-ouest qui a reçu la sépulture. Sa profondeur maximale sous la semelle de labour était de l'ordre de $0,80 \mathrm{~m}$.

\section{LA CHAMBRE LITHIQUE}

Délimitée par sept dalles de grès, la chambre lithique épousait la forme de la fosse sur trois de ses cotés (fig. 4 et 5). La paroi sud-ouest était délimitée par deux dalles subverticales jointives posées sur une sorte de banquette, la plus petite n'atteignait pas le fond de la fosse mais était calée par deux petites pierres. La paroi nord-est était constituée de deux dalles verticales posées sur le fond de la fosse. Le petit interstice qui les sépare avait été soigneusement bouché par deux petites pierres. Le petit côté au nord-ouest était délimité par une dalle subrectangulaire calée entre les parois latérales par deux pierres verticales. La paroi sud-est était engagée entre les montants latéraux et assez fortement inclinée vers l'intérieur du coffre. Elle se compose de deux plaques de grès peu épaisses qui correspondent en fait à la même dalle cassée selon un joint de stratification. La plaque externe a été retournée et plaquée contre l'autre en position décalée, de façon à obturer ce coté du coffre. Si la base de ces plaques est en correspondance étroite avec les extrémités des montants latéraux, leur sommet est nettement engagé dans le coffre et l'ensemble ne pouvait être maintenu ainsi que si cette paroi, plus élevée que les dalles latérales, prenait appui sur les dalles de couverture. Ce dispositif a donc été placé en dernier, puis bloqué par d'autres pierres disposées au fond du dégagement réservé au sud-est dont on comprend mieux, de ce fait, la fonction en tant que vestibule permettant l'accès puis la condamnation de la tombe (fig. 6).

L'espace funéraire ainsi délimité est de forme rectangulaire, il mesure à la base $1,70 \mathrm{~m}$ de long sur $0,80 \mathrm{~m}$ à $0,90 \mathrm{~m}$ de large. L'axe longitudinal de la tombe est orienté à $122^{\circ}$ par rapport au nord magnétique actuel, soit une direction proche du sud-est pour la dalle servant de porte de condamnation frontale. Cette orientation est fréquente dans le mégalithisme du Néolithique final-Chalcolithique du piémont nord-pyrénéen, mais elle ne semble pas systématique pour les coffres ou cistes des périodes antérieures (ceux de Najac sont orientés vers l'ouest, ceux de Dela Laïga à Cournanel, vers le sud-ouest).

Il est donc possible d'affirmer que la tombe de Coste Rouge est une chambre submégalithique souterraine établie dans une fosse. Ce type architectural, longtemps confondu avec les coffres, est reconnu ici, notamment grâce l'existence d'un vestibule pour la mise en place d'une fermeture engagée s'appuyant sur la dalle de couverture, et aussi par les dimensions relativement importantes de l'espace funéraire. Ce sont des caractères peu fréquents qui révèlent des affinités avec certains monuments du Solsonien, comme celui de Costa dels Garrics del Caballol II à Pinell dans le Solsonès (Catalogne). Sur ce site, la fouille des abords de la chambre lithique a permis de constater que sa fermeture avait été faite à partir d'un vestibule au moyen de trois dalles frontales se chevauchant qui dépassaient le niveau des montants latéraux et devaient s'appuyer sur la couverture (Castany, 1990). C'est sans doute ce vestibule qui a permis la réutilisation de la tombe pour quatre individus avant qu'il ne soit condamné par un amas de pierres. Cette observation a eu pour conséquence une révision de nombreux monuments de cette région qui semblent pour la plupart présenter les mêmes caractéristiques, avec cependant un espace de dégagement de l'accès qui est systématiquement orienté à l'ouest (Cura Morera, 1992).

\section{LA SÉPULTURE, DONNÉES ANTHROPOLOGIQUES \\ POSITION DES RESTES OSSEUX ET TAPHONOMIE}

Le sujet reposait au fond de la fosse en position légèrement excentrée vers l'ouest du coffre ; hormis le crâne surélevé, l'ensemble du corps se trouvait dans une gouttière dont le fond était nettement en dessous de la base des dalles (fig. 7).

Il s'agit d'un enfant qui a été déposé allongé sur le dos dans le même axe que le coffre (fig. 8). La tête était disposée au nord-ouest et venait en appui contre l'extrémité de la gouttière qui remonte assez brutalement, ce qui a induit un redressement progressif du rachis cervical. L'atlas et l'axis apparaissaient en vue antéro-supérieure ; de ce fait 


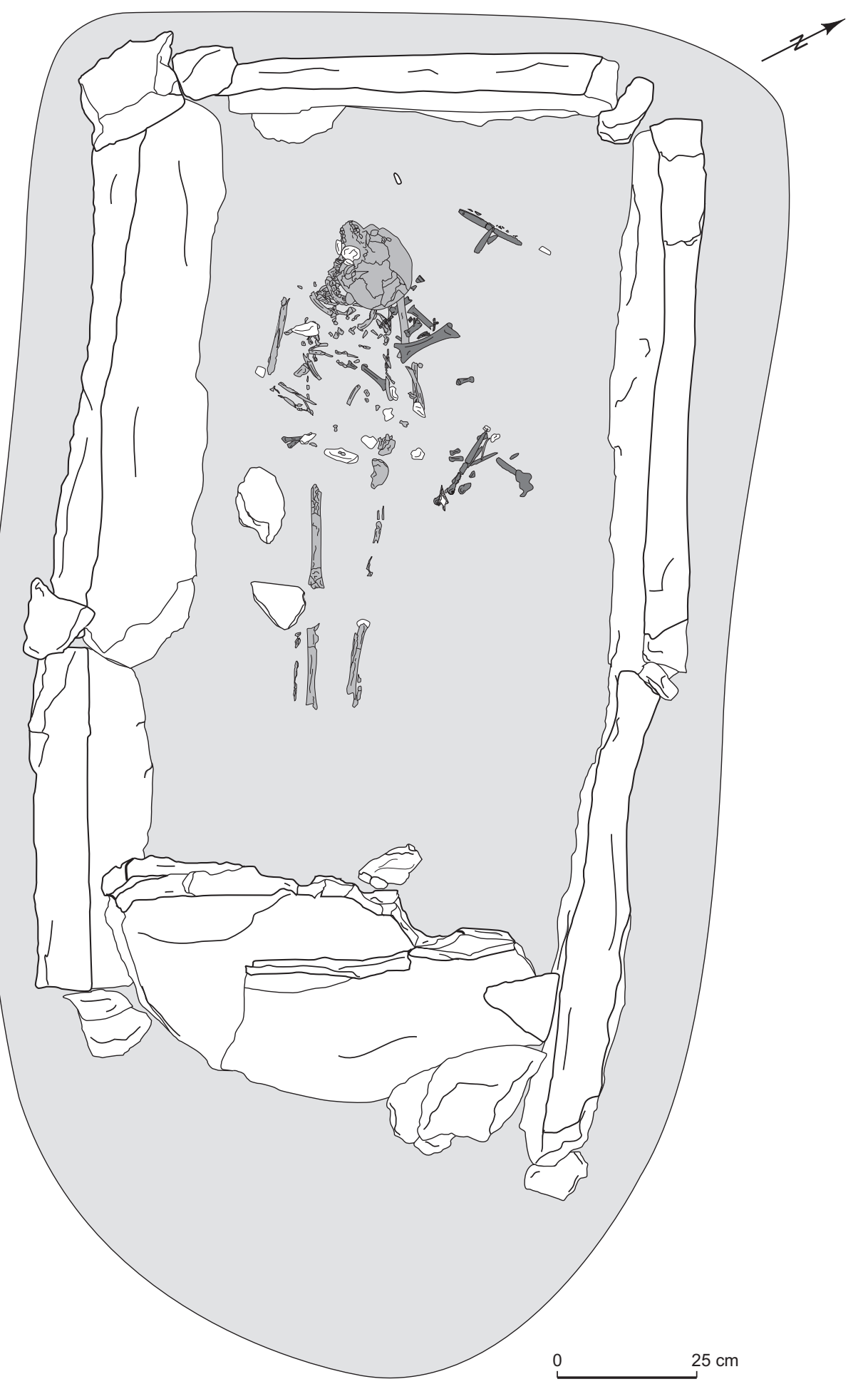

Fig. 7 - Tombe de Coste Rouge à Beaufort (Hérault). Position de la sépulture et du mobilier dans la chambre (DAO : M. Gandelin ; relevés anthropologiques : H. Duday, CNRS). 


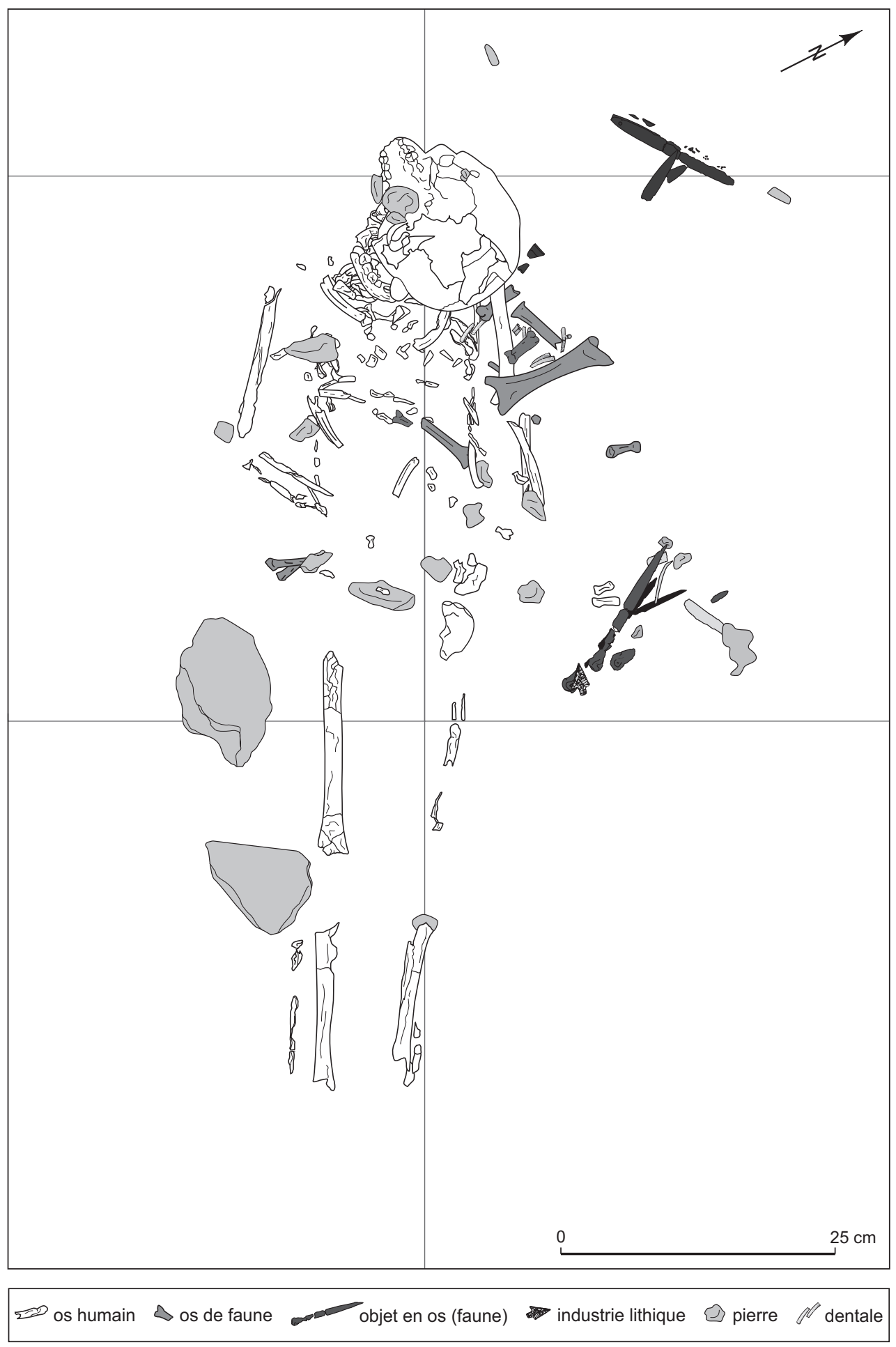

Fig. 8 - Tombe de Coste Rouge à Beaufort (Hérault).

Relevé de la sépulture (DAO : M. Gandelin ; relevés anthropologiques : H. Duday, CNRS). 
la mandibule reposait en avant du cou et même de la partie antéro-supérieure du thorax, et conformément à la position des vertèbres cervicales, elle apparaissait en vue supérieure. À l'origine, la tête se trouvait donc en position surélevée et devait apparaître en vue supéro-antérieure, la face tournée vers le sud-est. Après la disparition des contensions articulaires, elle a subi un remaniement sur place puisqu'elle se présentait en vue inféro-latérale gauche, la face dirigée vers le nord-ouest (fig. 9a).

Le basculement du crâne sur place n'a pu intervenir que dans un espace vide ; toutefois la cause de ce mouvement ne peut être déterminée: on peut envisager une cause naturelle comme l'infiltration brutale d'eau ou l'intrusion d'un animal fouisseur, mais l'éventualité d'une cause anthropique impliquant l'ouverture de la tombe et la manipulation du crâne remis ensuite en place dans une mauvaise position ne peut être totalement écartée. C'est sans doute au cours de ce mouvement du crâne qu'une des deux incisives centrales supérieures retrouvées déchaussées est allée se loger entre la clavicule gauche et le condyle de la mandibule, tandis que l'autre se trouvait plus ou moins à l'aplomb de sa position originelle. Le reste du squelette était assez mal conservé ; les os ont subi une attaque chimique qui a fait disparaître la majeure partie des vertèbres, des os du bassin, les épiphyses des os longs et les petits os des mains et des pieds. De surcroît certaines parties, comme la cage thoracique et le reste du tronc, ont manifestement subi des perturbations liées au passage de terriers.

Les éléments subsistants montrent que le coude droit était légèrement fléchi, le poignet et sans doute la main ramenés sur le flanc droit mais dont il ne reste en place qu'une seule phalange distale. Le membre antérieur gauche en extension était, quant à lui, en légère abduction vers la gauche avec la main tendue vers un dépôt de mobilier (fig. 9b). Comme la gouttière se resserrait au niveau des épaules, la gauche, mieux conservée, était projetée vers l'avant. La clavicule gauche était oblique et l'humérus présentait un fort pendage dans le sens proximo-distal $(9 \mathrm{~cm}$ entre les deux extrémités), l'avant-bras se présentait en vue antérieure. De la main gauche, il ne subsiste que trois phalanges plus ou moins en place, deux en vue palmaire et l'autre en vue dorsale, ce qui ne permet pas de définir sa position. Le bassin n'est représenté que par un fragment d'ilium gauche (face médiale). Des membres inférieurs, il ne restait que les diaphyses des os longs qui indiquent qu'ils étaient parallèles et en extension.

Hormis le crâne, qui a subi un mouvement important impliquant une décomposition du corps en espace vide,

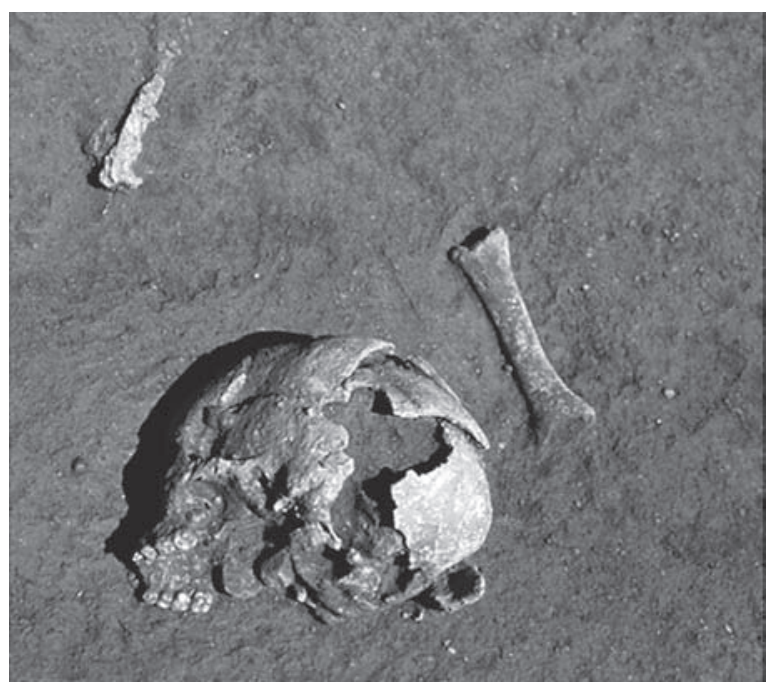

a

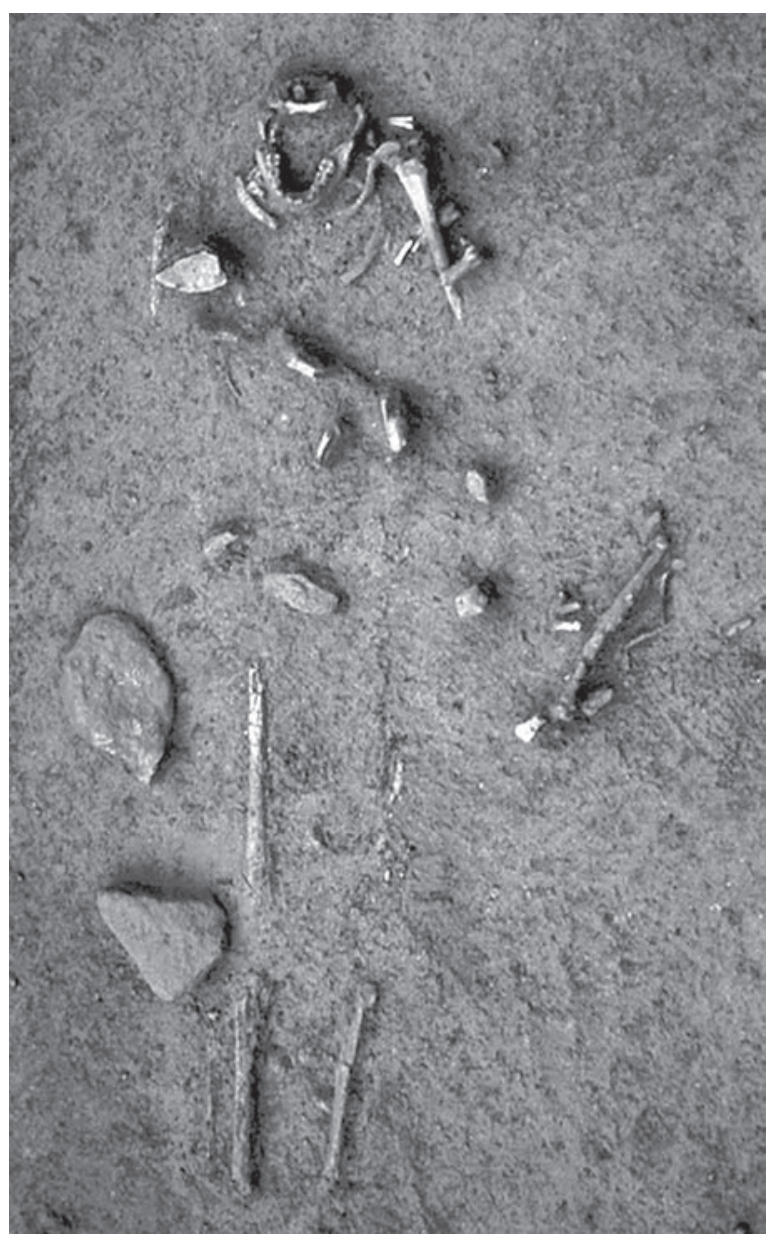

b

Fig. 9 - Tombe de Coste Rouge à Beaufort (Hérault). Vues du décapage du niveau sépulcral : a, relevé 1 ; b, relevé 2 (clichés :J. Vaquer, CNRS). 
Tabl. I - Sépulture de Coste Rouge à Beaufort (Hérault). Tableau de mesures du bloc crânio-facial de l'enfant inhumé. Les valeurs sont données en millimètres. Chaque mesure $(M)$ est assortie, dans la seconde colonne, de sa désignation conventionnelle utilisée en anthropologie d'après la nomenclature de Martin, 1957.

\begin{tabular}{|l|c|c|l|}
\hline Longueur maximale & M1 & 163 & environ : occipital enfoncé à l'intérieur du crâne (surtout côté gauche) \\
\hline Largeur maximale transversale & M8 & 122 & environ : pariétal droit abîmé au niveau de la bosse pariétale \\
\hline Largeur frontale minimale & M9 & 83 & \\
\hline Hauteur basion-bregma & M17 & 112 & \\
\hline Longueur de la base & M5 & 80 & \\
\hline Longueur de la face & M40 & 74 & environ : zone du prosthion érodée \\
\hline Hauteur faciale supérieure & M48 & 48 & \\
\hline Largeur orbite gauche & M51 & 32 & \\
\hline Hauteur orbite gauche & M52 & 29,7 & \\
\hline Porion droit-bregma & & 108 & \\
\hline Porion gauche-bregma & & 105 & \\
\hline Porion-porion & & 93 & \\
\hline Hauteur porion-bregma & M20 & 117,6 & reconstruction géométrique \\
\hline Arc frontal & M26 & 93,3 & \\
\hline Arc pariétal & M27 & 109,2 & \\
\hline Corde frontale & M29 & 107 & \\
\hline Corde pariétale & M30 & 118 & \\
\hline
\end{tabular}

le reste $\mathrm{du}$ squelette se trouve en position anatomique cohérente pour toutes les parties situées au fond de la fosse qui a dû être colmatée assez rapidement. Il s'agit donc d'un dépôt primaire en ambiance confinée qui a subi un remaniement d'origine naturelle (voire anthropique) limité au crâne. Par la suite, le comblement définitif a dû se mettre en place par infiltration et c'est ainsi que quelques vestiges préhistoriques (charbons, graines carbonisées, menus tessons modelés atypiques, quelques silex) ont pu être trouvés dans le comblement supérieur du coffre. D’autres remaniements liés à des terriers ont dû intervenir ultérieurement et expliquent les perturbations observées au niveau du tronc ou la remontée de certains vestiges (dentales et pointe à pédoncule et ailerons en silex) trouvés dans le comblement supérieur de la chambre.

\section{ÉTUDE ANTHROPOLOGIQUE}

\section{ÉTATS DE CONSERVATION DES RESTES OSSEUX}

Les documents de fouille (relevés et photographies) montrent que la conservation du squelette était très défectueuse, même si la disposition des os dans la tombe respectait une logique anatomique. Le nettoyage et la préparation du matériel ont été réalisés par M. Bessou, technicienne de recherche au Laboratoire d'anthropologie des populations du passé (LAPP, Université Bordeaux-I).

Le bloc crânio-facial, très mince et déminéralisé, a dû être consolidé en bloc ; il était en effet impossible d'enlever le sédiment contenu dans le crâne sans prendre le risque de voir celui-ci se briser de manière irréparable. Il a ainsi été possible de relever quelques mesures (tabl. I) ; en contrepartie, les radiographies de l'arcade dentaire supérieure sont peu lisibles en raison de l'opacité de la terre.

Le squelette est donc très incomplet (fig. 10). Les diaphyses des grands os longs des membres sont seulement conservées dans la partie centrale du fût diaphysaire, à l'exception de l'humérus et de la clavicule gauches qui sont pratiquement complets. On note d'ailleurs que les os de l'épaule gauche sont en meilleur état de conservation que le reste du squelette, puisque la partie latérale de la scapula gauche a également été retrouvée : sans doute cela tient-il au fait que cette partie du corps a été protégée par le bloc crânio-facial basculé (?). D’une manière générale, les portions spongieuses du squelette ont disparu : ainsi, pour la colonne vertébrale, nous ne disposons que de certains arcs postérieurs (vertèbres cervicales et première thoracique, plus les fragments de trois thoraciques moyennes de rang indéterminé) ; le seul corps vertébral qui subsiste est celui de l'axis. 


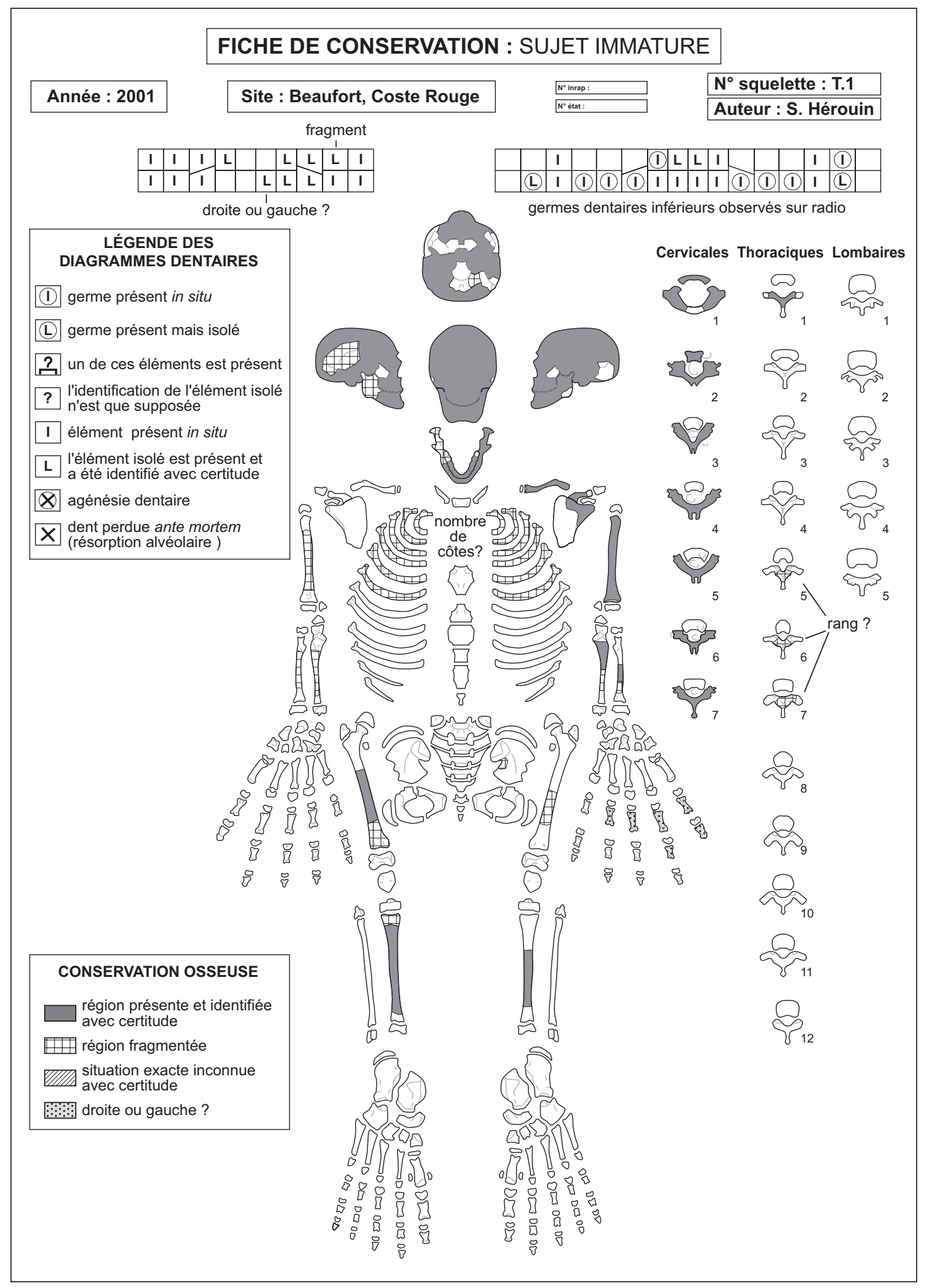

Fig. 10 - Tombe de Coste Rouge à Beaufort (Hérault).

Fiche d'état de conservation des restes osseux de l'individu (DAO : M. Coutureau, INRAP). 


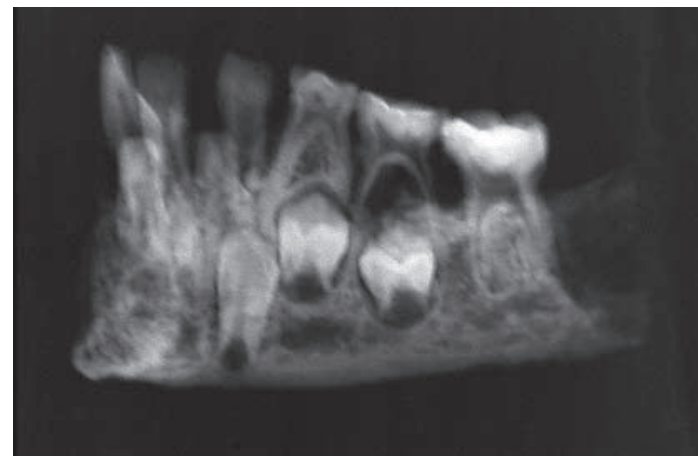

a

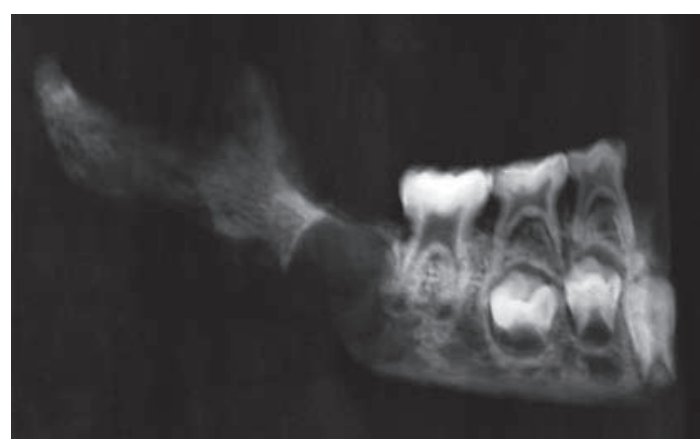

b

Fig. 11 - Tombe de Coste Rouge à Beaufort (Hérault). Radiographies de la mandibule inférieure de l'individu : a, profil droit ; b, profil gauche (clichés: M. Bosson, LAPP, Université de Bordeaux-I).

Les corticales compactes sont amincies, avec de nombreux sillons vermiculés qui signent l'action ostéolytique des racines végétales. De ce fait, les mensurations transversales (diamètres et périmètres) seront données par défaut.

\section{DÉTERMINATION DE L'ÂGE AU DÉCÈS}

L'estimation de l'âge au décès a été réalisée à partir de la dentition, qui est présentée de manière synthétique dans le schéma de conservation (fig. 10) pour les dents déciduales (à gauche) et permanentes (à droite). L'examen direct et les radiographies de la mandibule (fig. 11) permettent de préciser la maturation de chacune des dents, cotée selon les recommandations de Moorrees, Fanning et Hunt (1963a et b) : Crc, couronne complète ; Ri, début de formation de la racine, à proximité immédiate du collet; R1/4, R1/2, $\mathrm{R} 3 / 4$, racine formée au quart, à la moitié ou aux trois quarts de sa longueur définitive ; Rc, racine complète, mais apex béant ; A1/2, apex à demi fermé ; Ac, apex fermé ; Res1/2, résorption de la racine (dent déciduale) sur la moitié de sa hauteur. Comme nous l'avons signalé précédemment, les
Tabl. II - Sépulture de Coste Rouge à Beaufort (Hérault). Inventaire et degré de calcification des dents; pour chaque dent est indiqué le stade de formation de la couronne, de la racine et éventuellement le degré de résorption de celle-ci. Les lettres minuscules désignent les dents déciduales, les lettres majuscules les dents permanentes: $i, I$ : incisives ; $c, C$ : canines ; $P$ : prémolaires ; $m, M:$ molaires. Les chiffres en exposant et l'apostrophe correspondent aux dents supérieures, les chiffres en indice et la virgule aux dents inférieures. Les lettres $D$ et $G$, désignent les dents de droite et de gauche. Le nombre à deux chiffres indiqué entre parenthèses pour chaque dent correspond à la désignation de celle-ci dans la nomenclature odontologique internationale.

\begin{tabular}{|c|c|c|c|c|c|}
\hline \multicolumn{3}{|c|}{ Dents supérieures } & \multicolumn{3}{|c|}{ Dents inférieures } \\
\hline \multirow{2}{*}{$\mathbf{i}^{1}$} & $D(51)$ & & \multirow{2}{*}{$\mathbf{i}_{1}$} & $\mathrm{D}(81)$ & \\
\hline & $\mathrm{G}(61)$ & & & $\mathrm{G}(71)$ & \\
\hline \multirow{2}{*}{$\mathbf{i}^{2}$} & $D(52)$ & $\operatorname{Res} 1 / 2$ & \multirow[b]{2}{*}{$\mathbf{i}_{2}$} & $\mathrm{D}(82)$ & $\operatorname{Res} 1 / 2 \mathrm{D}$ ou $\mathrm{G} ?$ \\
\hline & $\mathrm{G}(62)$ & $\operatorname{Res} 1 / 2$ & & $\mathrm{G}(72)$ & \\
\hline \multirow{2}{*}{$c^{\prime}$} & D (53) & Ac & \multirow{2}{*}{ C, } & D (83) & Ac \\
\hline & G (63) & Ac & & G (73) & Ac \\
\hline \multirow{2}{*}{$\mathbf{m}^{1}$} & D (54) & Ac & \multirow{2}{*}{$m_{1}$} & D (84) & $A c$ \\
\hline & G (64) & & & G (74) & Ac \\
\hline \multirow{2}{*}{$\mathbf{m}^{2}$} & $D(55)$ & $A c$ & \multirow{2}{*}{$\mathbf{m}_{2}$} & D (85) & Ac \\
\hline & G (65) & Ac & & $G(75)$ & Ac \\
\hline \multirow{2}{*}{$\mathbf{I}^{1}$} & $\mathrm{D}(11)$ & $\operatorname{Res} 1 / 2$ & \multirow{2}{*}{$I_{1}$} & $\mathrm{D}(41)$ & Rc \\
\hline & $\mathrm{G}(21)$ & $\operatorname{Res} 1 / 2$ & & G (31) & Rc \\
\hline \multirow{2}{*}{$\mathbf{I}^{2}$} & $\mathrm{D}(12)$ & $>=\mathrm{Cr} 2$ & \multirow{2}{*}{$I_{2}$} & $D(42)$ & R $3 / 4$ \\
\hline & G (22) & $>=\mathrm{Cr} 2$ & & G (32) & $\mathrm{R} 3 / 4$ \\
\hline \multirow{2}{*}{$\mathbf{C}^{\prime}$} & $\mathrm{D}(13)$ & & \multirow{2}{*}{ C, } & D (43) & R $1 / 2$ \\
\hline & G (23) & & & G (33) & R $1 / 2$ \\
\hline \multirow{2}{*}{$\mathbf{P}^{1}$} & D (14) & & \multirow{2}{*}{$P_{1}$} & D (44) & R $1 / 4$ \\
\hline & G (24) & & & G (34) & R $1 / 4$ \\
\hline \multirow{2}{*}{$\mathbf{P}^{2}$} & $\mathrm{D}(15)$ & & \multirow{2}{*}{$\mathbf{P}_{2}$} & $\mathrm{D}(45)$ & R $1 / 4$ \\
\hline & G (25) & & & G (35) & R $1 / 4$ \\
\hline \multirow{2}{*}{$\mathbf{M}^{1}$} & $\mathrm{D}(16)$ & $A 1 / 2$ à $A c$ & \multirow{2}{*}{$\mathbf{M}_{1}$} & D (46) & A $1 / 2$ \\
\hline & G (26) & $A 1 / 2$ à $A c$ & & G (36) & A $1 / 2$ \\
\hline \multirow{2}{*}{$\mathbf{M}^{2}$} & $\mathrm{D}(17)$ & & \multirow{2}{*}{$M_{2}$} & D (47) & Crc à Ri \\
\hline & G (27) & $\mathrm{Ri}$ & & G (37) & Crc à Ri \\
\hline \multirow{2}{*}{$\mathbf{M}^{3}$} & $\mathrm{D}(18)$ & & \multirow{2}{*}{$\mathbf{M}_{3}$} & $D(48)$ & \\
\hline & G (28) & & & G (38) & \\
\hline
\end{tabular}

radiographies des maxillaires n'ont pas pu être exploitées pour l'estimation du stade de formation des dents supérieures; parmi celles-ci, seules celles qui étaient directement observables ont pu être cotées.

Les indications regroupées dans le tableau II ont été traitées selon la méthode de diagnose probabiliste élaborée par F. Houët au Laboratoire d'anthropologie des populations du passé. En tenant compte des diverses possibilités 


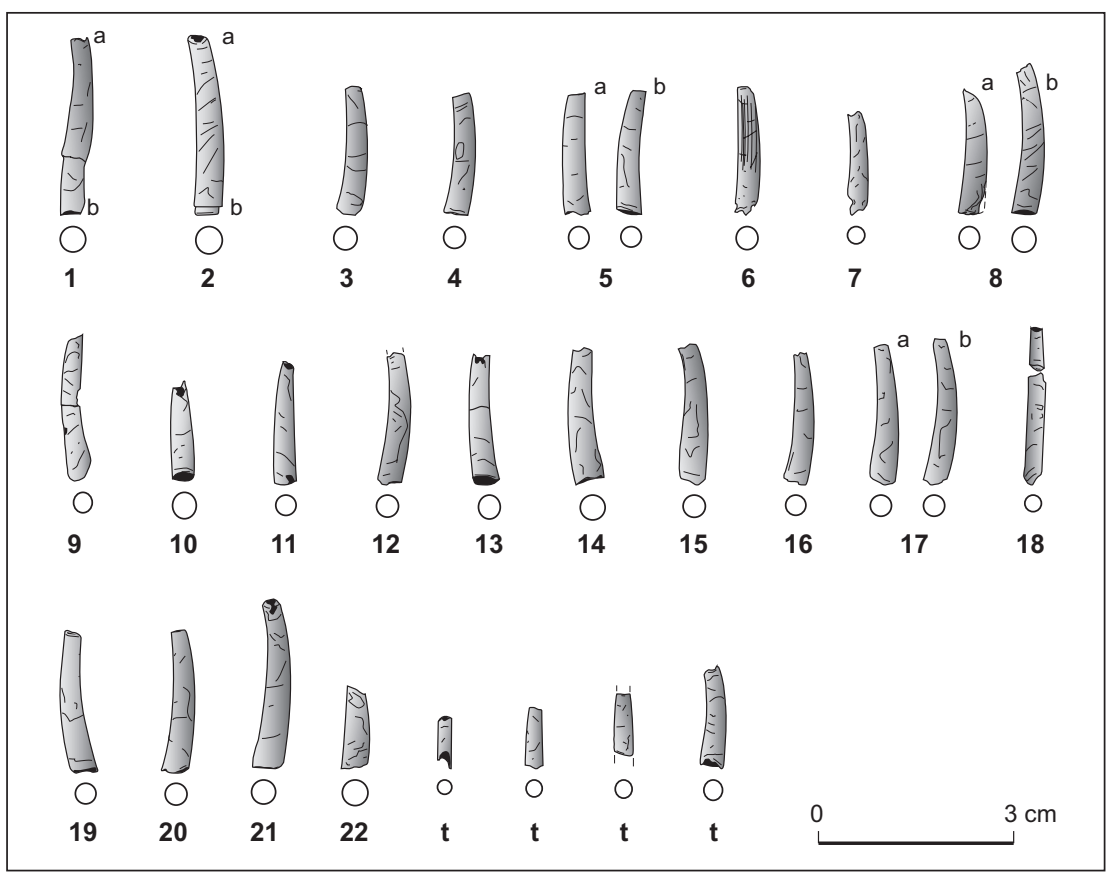

Fig. 12 - Tombe de Coste Rouge à Beaufort (Hérault). Éléments de parure en coquilles de dentales; $t$ : trouvé au tamis (DAO: M. Gandelin).

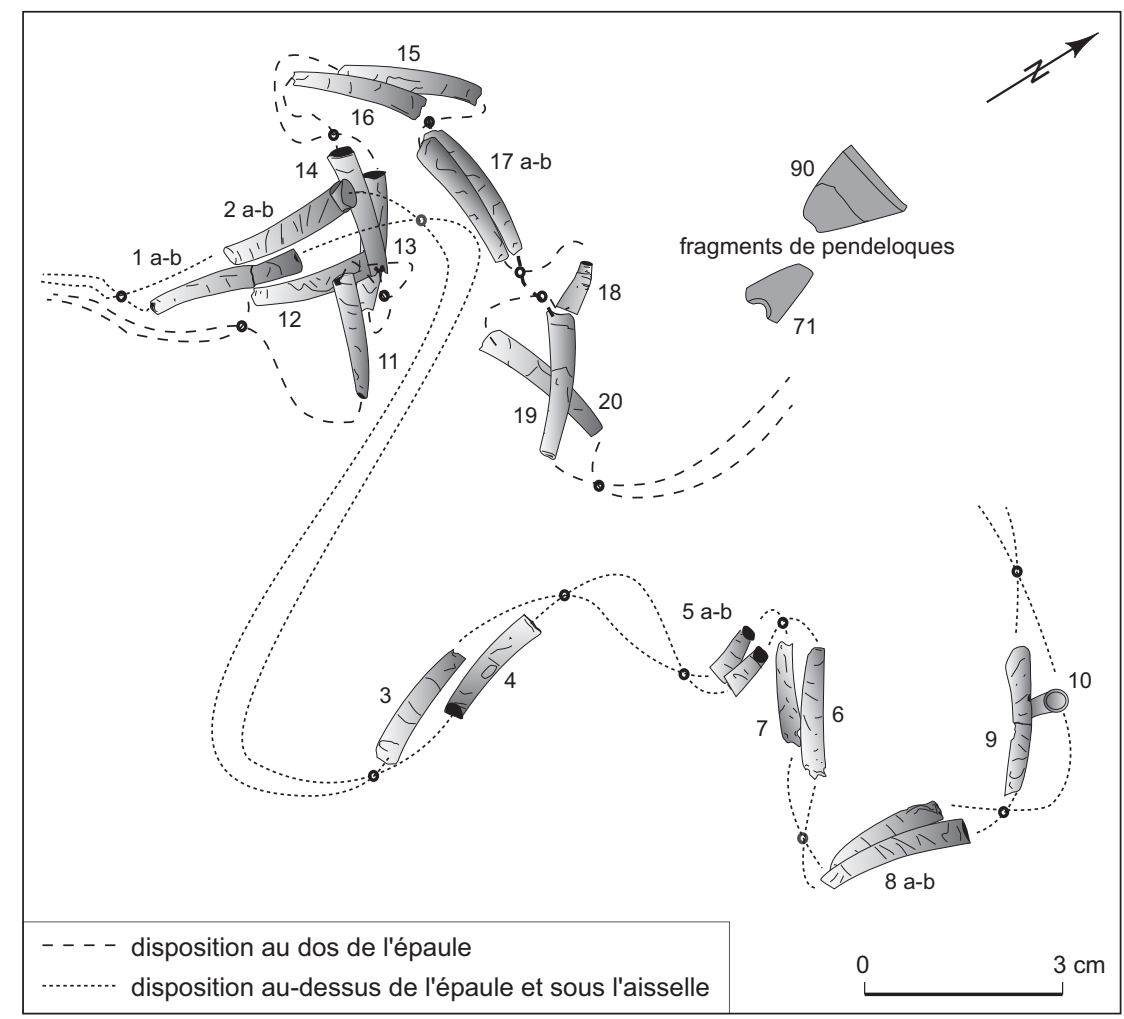

Fig. 13 - Tombe de Coste Rouge à Beaufort (Hérault). Disposition des dentales et tracé possible des liens d'assemblage (en pointillés au-dessus de l'épaule et sous l'aisselle et en tireté au dos de l'épaule) (DAO : M. Gandelin). 
lorsqu'une dent se trouvait à un stade intermédiaire ou indéterminé entre deux des stades de référence, on peut situer l'âge au décès entre 5 et 8 ans, avec un risque d'erreur inférieur à 1/1000.

Lors de la fouille, nous avions été frappés par l'apparente gracilité des os longs en comparaison de la dentition. L'érosion des corticales rend cependant incertaines les mensurations transversales. Les seuls os effectivement mesurables sont l'humérus et la clavicule gauches.

\section{Humérus gauche}

Longueur maximale

Diamètre transversal au milieu

Diamètre sagittal au milieu

$\geq 148 \mathrm{~mm}(\leq 150 \mathrm{~mm})$;

Périmètre au milieu

$10,9 \mathrm{~mm}$;

$10,3 \mathrm{~mm}$;

$35,5 \mathrm{~mm}$.

\section{Clavicule gauche}

Longueur maximale

$\leq 80 \mathrm{~mm}$;

Diamètre sagittal au milieu

$6,5 \mathrm{~mm}$;

$8,0 \mathrm{~mm}$.

La diagnose probabiliste appliquée à la longueur diaphysaire de l'humérus gauche donne un âge compris entre 3 et 7 ans, avec un risque d'erreur inférieur à 5/100. Certes, il existe donc bien un décalage entre les résultats que donnent les dents et la métrique, sans toutefois que l'on puisse retenir un hypostaturisme pathologique.

En conclusion, on retiendra pour cet enfant un âge au décès compris entre 5 et 7 ans. La diagnose sexuelle est impossible à partir des caractères morphologiques d'un squelette d'enfant aussi jeune.

\section{LE MOBILIER FUNÉRAIRE}

Le mobilier peut être scindé en trois lots distincts :

- un ensemble d'objets de parure localisé à gauche du crâne et autour de l'épaule gauche ;

- un lot d'outils disposé dans le prolongement de la main gauche ;

- des os de faune répartis sur l'épaule gauche, le thorax et sous le poignet droit (fig. 8).

\section{LES ÉLÉMENTS DE PARURE}

\section{LA PARURE EN DENTALES}

La sépulture a livré une série de 31 dentales appartenant à l'espèce Dentalium dentale ou à l'espèce Dentalium vulgare Da Costa, comme l'indique la présence de fines stries longi- tudinales parfois observables sur les exemplaires les mieux conservés, notamment le $\mathrm{n}^{\circ} 6$ (fig. 12). Ces petits coquillages de scaphopodes marins en forme de tube arqué, qui se trouvent sur les côtes sableuses, n'ont pas été utilisés entiers mais tronçonnés ou abrasés vers la partie la plus étroite, sans doute pour faciliter le passage d'un lien et obtenir des modules compris entre $2,3 \mathrm{~cm}$ et $3,3 \mathrm{~cm}$ de long avec une moyenne de 2,7 cm. Leurs extrémités sont souvent usées, parfois avec une légère encoche. Pour plus de la moitié, ces éléments peuvent être considérés comme entiers, les autres ont subi des dégradations de type mécanique ou chimique parfois assez accentuées, ce qui laisse penser que leur nombre originel pouvait être plus élevé.

Hormis deux exemplaires retrouvés dans le remplissage supérieur du coffre en position remaniée et quatre autres récupérés par tamisage à l'eau du sédiment du fond de la tombe, la majorité de ces coquillages se trouvait en place dans le secteur de l'épaule et du bras gauche. Leur position sur le terrain permet une série de déductions (fig. 13). Tout d'abord, il est manifeste que ces éléments étaient regroupés par deux. Plusieurs couples parfaitement ajustés ont pu être observés en position horizontale (17a et b, 6 et 7, 8a et b, $5 \mathrm{a}$ et $\mathrm{b})$, d'autres ne sont que très légèrement décalés (15-16, 13-14, 3-4), ils peuvent être croisés (19-20), voire perpendiculaires (12-11 et 9-10). Un seul de ces couples est formé de quatre dentales profondément enchâssés deux par deux (1a et b, 2a et b). Une telle disposition d'ensemble sur deux rangs et par couples distincts implique un montage avec un système séparatif, soit au moyen de nœuds, soit par des éléments intercalaires en matière organique qui auraient disparu ; il est également possible que les dentales aient été cousus sur un ruban souple ou la lisière d'un vêtement.

La position de ces éléments par rapport aux os humains permet de discuter la question du port de cette parure en coquillages (fig. 14 et 15). Bien que le crâne ait recouvert la zone où ils se trouvaient, on peut éliminer d'emblée leur participation à une parure de tête dans la mesure où plusieurs éléments se trouvaient engagés sous la scapula gauche. Leur rattachement à un collier est plausible mais ne peut être prouvé, car aucun dentale n'a vraiment été trouvé sous ou autour des vertèbres cervicales. Il faudrait admettre que si les liens passaient autour du cou, ils n'étaient pas revêtus de dentales dans cette zone et que cet éventuel collier était entièrement déporté sur le coté gauche de l'individu. En fait, la disposition des éléments en place suggère une organisation autour de l'épaule gauche: les exemplaires emboîtés ( $1 \mathrm{a}$ et b et $2 \mathrm{a}$ et b) se trouvaient sur le haut de l'épaule entre la mandibule, la clavicule et l'arête 


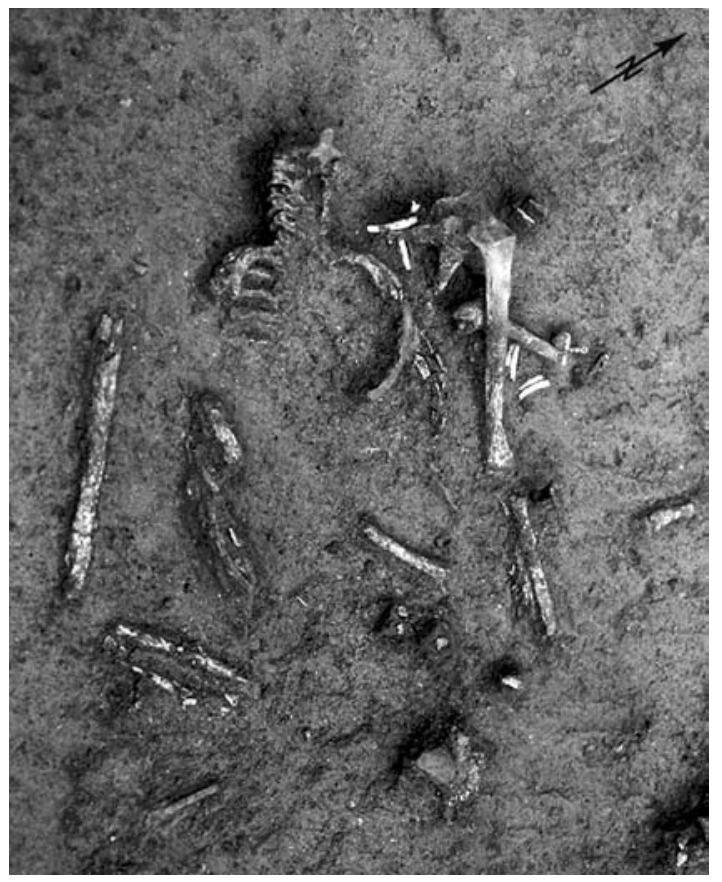

Fig. 14 - Tombe de Coste Rouge à Beaufort (Hérault). Vue de détail des éléments de parure en dentales en place (cliché: J. Vaquer, CNRS).

supérieure de la scapula, deux autres exemplaires (3 et 4) se trouvaient sur le versant antéro-latéral gauche de la cage thoracique. Il est probable qu'ensuite l'élément passait sous l'aisselle ; en effet le dentale 4 était engagé sous la phalange d'ours, elle-même coincée sous l'humérus, pour ressortir au-delà du bras gauche à partir du couple de dentales en position verticale ( $5 \mathrm{a}$ et b) et jusqu'aux exemplaires 9 et 10 qui marquent le début d'une lacune dans une zone peutêtre remaniée par un terrier. Tous les autres dentales se trouvaient sur la partie dorsale de l'épaule, soit clairement engagés sous la scapula, soit autour et au niveau de sa base. S'il s'agit d'un collier, il était donc porté en bandoulière, mais on peut imaginer aussi qu'il puisse s'agir d'une parure d'épaule portée comme une fourragère, voire d'une écharpe ou d'une bretelle de vêtement (ou de sac) décorée de dentales cousus.

Dans le midi de la France, l'utilisation de dentales pour la parure est attestée dès le Néolithique ancien (grotte 4 de Saint-Pierre-de-la-Fage dans l'Hérault), elle est avérée dans quelques ensembles chasséens et se poursuit ensuite jusqu'à l'âge du Bronze moyen, comme par exemple dans la sépulture de l'abri du Collier à Lastours (Aude). Généralement les assemblages de dentales sont interprétés comme faisant partie de colliers où ils sont parfois associés à d'autres types de perles dans les ensembles chalco- lithiques les mieux conservés (Barge, 1982). Les mêmes tendances chronologiques sont observables en Catalogne. Dans la culture des Sepulcros de fosa, des groupes de dentales ont été observés en place, mais ils ne correspondent pas à des colliers. Dans la ciste d'Arceda à Llobera (Lérida), 72 dentales étaient regroupés vers les pieds (parure de chevilles ou éléments cousus sur des chaussures), dans la tombe de Bigas (Barcelona) des dentales associés à d'autres perles formaient un bracelet ou un brassard au niveau du poignet droit (Muñoz Amibilia, 1965).

\section{LES PENDENTIFS SUR PLAQUETTES OSSEUSES}

Les restes d'au moins cinq pendentifs allongés, réalisés sur de fines plaquettes tirées de parties corticales de côtes de grands ruminants, ont été trouvés dans la tombe à gauche du crâne, hors de la gouttière et donc en position légèrement surélevée par rapport au squelette. D’après la position de ces éléments relevée sur le terrain, il est possible d'affirmer que deux exemplaires à extrémité distale aiguë étaient orientés nord-sud et étaient situés entre l'arrière du crâne ou l'épaule gauche et le second groupe de pendentifs comportant les restes de trois exemplaires, disposés dans le sens ouest-est à une quinzaine de centimètres du temporal gauche (fig. 15). Ces éléments sont mal conservés, hormis les parties qui étaient recouvertes d'encroûtements calcaires. En prenant en compte un fragment cassé de frais au niveau de la perforation qui a été trouvé en dehors du coffre, sans doute dans les déblais du sondage réalisé au moment de la découverte (fig. $16, \mathrm{n}^{\mathrm{o}} 4$ ), les pièces attribuables à ces pendeloques sont au nombre de huit.

- Fragment proximal de forme trapézoïdale façonné par abrasion, comme l'indiquent des stries sur les deux faces. La perforation a été réalisée à partir de l'une des faces. Ce fragment a été trouvé à la base de l'arrière du crâne avec la perforation en direction de celui-ci, mais dans un secteur qui semble remanié par un terrier (fig. 16, $\mathrm{n}^{\mathrm{o}} 1$ ).

- Fragment mésial avec des traces de corrosion et de fractures anciennes. Il a été façonné par abrasion, comme le montrent de nombreuses stries sur la face supérieure. La face inférieure encroûtée présente des reliquats de tissu spongieux. Les bords sont équarris $(1,8 \mathrm{~mm})$. Il a été trouvé en position verticale et à proximité du précédent (fig. 16, $\mathrm{n}^{\circ}$ 2).

- Partie distale ogivale façonnée par abrasion, avec des stries sur la face supérieure et des reliquats de tissu spongieux sur la face inférieure. Les bords sont équarris et 


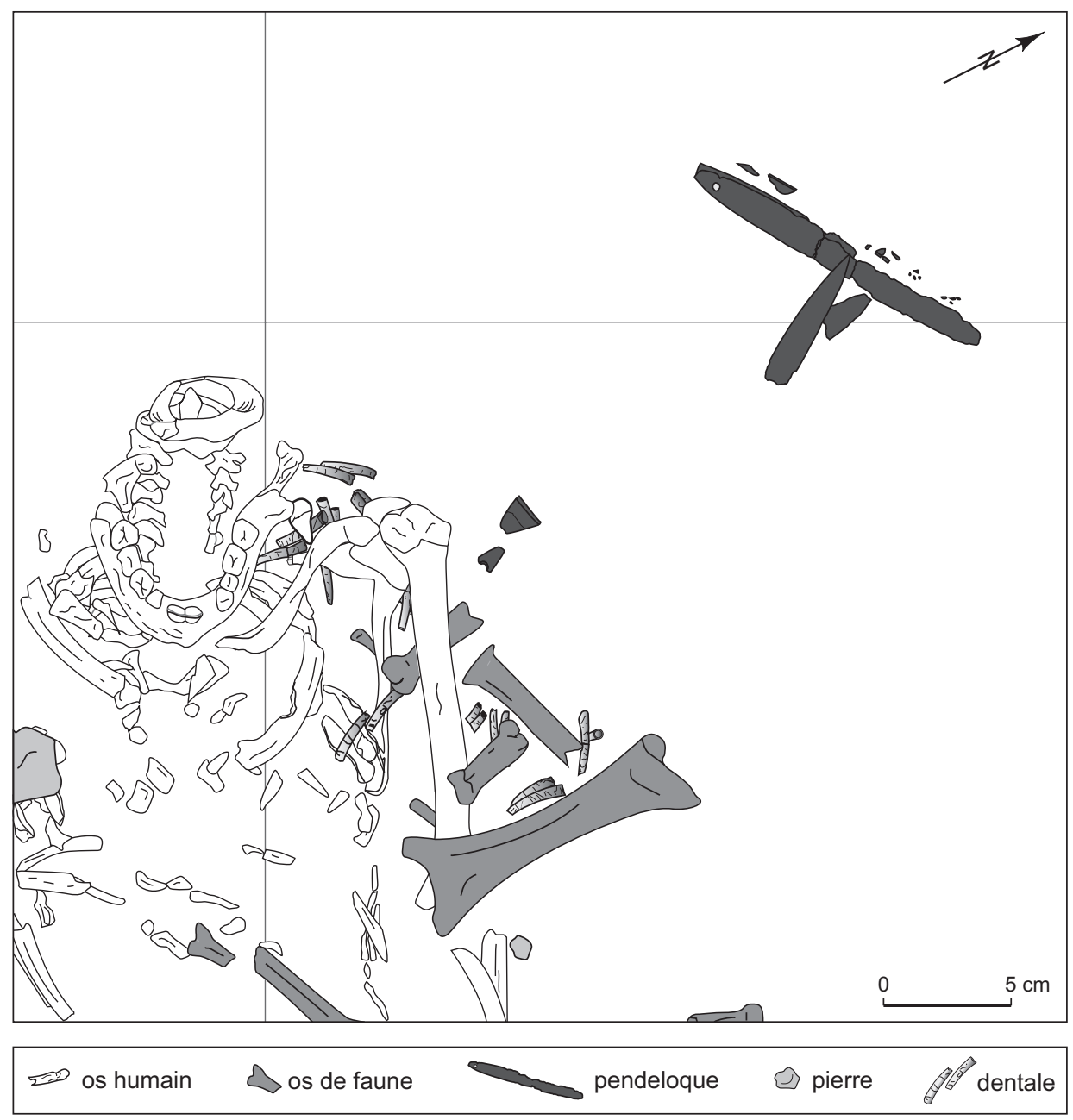

Fig. 15 - Tombe de Coste Rouge à Beaufort (Hérault). Organisation des dentales, des os de faune et des pendeloques par rapport aux os humains (DAO: M. Gandelin; relevés anthropologiques: H. Duday, CNRS).

l'extrémité biseautée. La pointe recouvrait le second groupe de pendeloques (fig. 16, $\mathrm{n}^{\mathrm{o}} 3$ ).

- Partie proximo-mésiale cassée au niveau de la perforation qui a été réalisée à partir de la face inférieure. La face supérieure est corrodée, avec tout de même des plages lisses à stries d'abrasion. La face inférieure présente des reliquats de tissu spongieux. Cette pièce a été trouvée à une trentaine de centimètres au nord-ouest de la chambre dans des sédiments remaniés (fig. 16, $\mathrm{n}^{\mathrm{o}} 4$ ).

- Extrémité sans doute pointue d'un exemplaire corrodé, dont la face supérieure présente une plage polie avec des stries d'abrasion. Cette pièce était engagée sous le $n^{\circ} 3$ et orientée approximativement de la même façon (fig. 16, $\mathrm{n}^{\circ} 5$ ).

- Pendentif pratiquement entier dont la partie proximale qui était encroûtée est relativement bien conservée et dont la partie distale est très fortement corrodée et a dû être consolidée in situ. La pièce devait mesurer $12,8 \mathrm{~cm}$ de long et 1,2 cm de large. Elle est arquée dans le sens longitudinal, ce qui implique qu'elle a été tirée de la face interne d'une côte. Elle a été façonnée par abrasion et la quasi-totalité du tissu spongieux de la face inférieure a été éliminée. L'encroûtement n'a pas pu être totalement enlevé au niveau de la perforation qui semble tout de même avoir été réalisée à partir de la face inférieure. Ce pendentif était disposé contre le suivant et orienté dans le même sens (fig. 16, $n^{\circ} 6$ ).

- Partie proximo-mésiale très fortement corrodée vers la base. La face supérieure est d'aspect concave (partie corticale interne d'une côte) et façonnée par abrasion. La face inverse montre des reliquats de tissu spongieux et c'est à partir d'elle qu'a été réalisée la perforation. Il est probable 

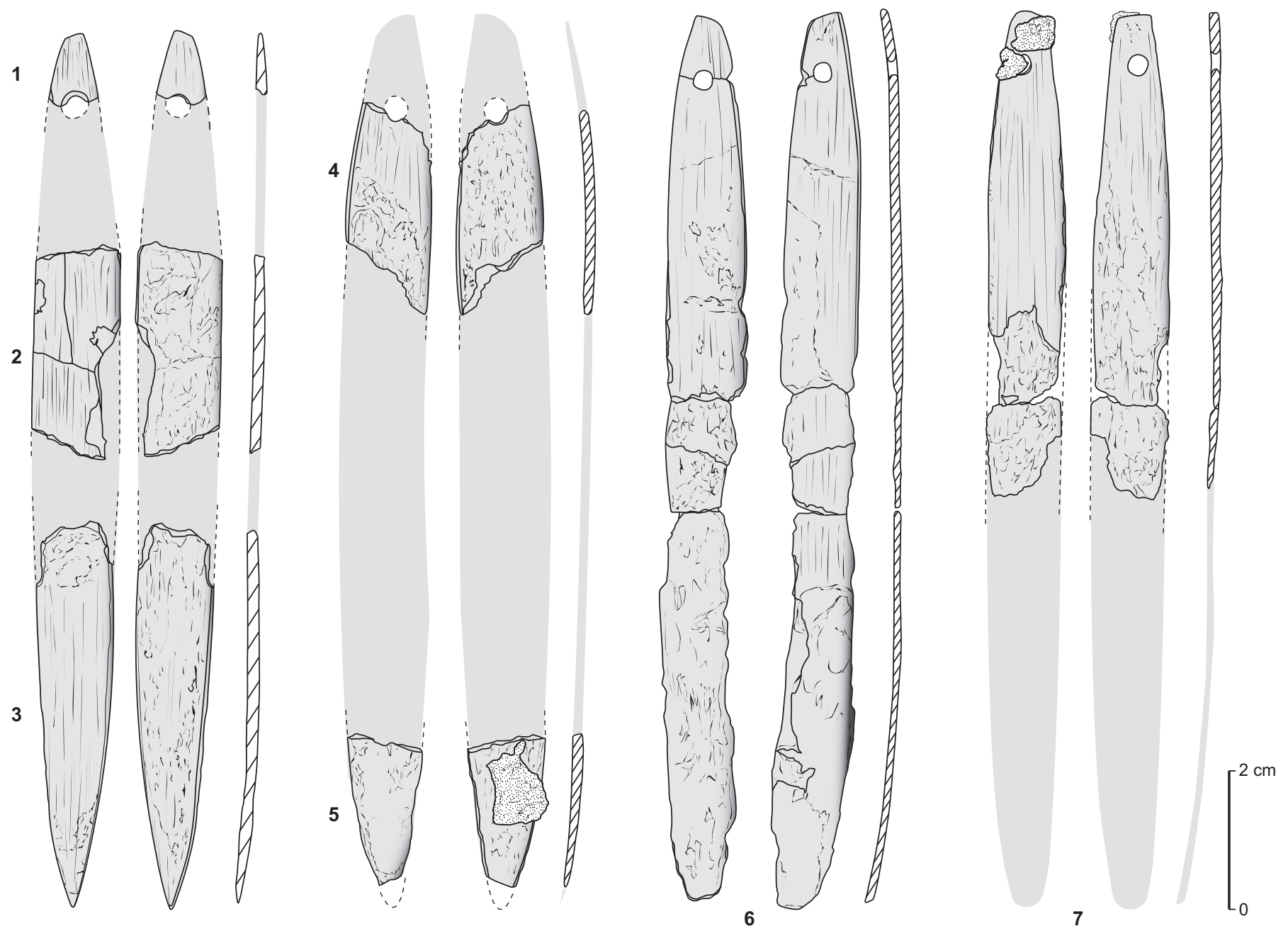

Fig. 16 - Tombe de Coste Rouge à Beaufort (Hérault).

Fragments de pendeloques en os et proposition de restitution (DAO : M. Gandelin et R. Marsac, ATA).

qu'il était identique au précédent et que la corrosion a fait disparaître toute la partie distale (fig. 16, $\mathrm{n}^{\mathrm{o}} 7$ ).

- À ces pièces s'en ajoute une autre qui se réduisait à d'infimes fragments, très corrodés, dont la disposition montre, tout de même, une orientation et une longueur équivalentes à celles des deux objets précédents.

Vu la fragilité et le mauvais état de conservation de ces pièces, il n'est pas exclu qu'elles aient pu être plus nombreuses à l'origine. Elles appartiennent à une classe d'objets généralement interprétés comme des pendeloques qui peuvent être de forme rectangulaire, elliptique ou fusiforme comme dans le cas présent, ce qui les rapproche de certaines aiguilles ou passe-fils, voire d'aiguillettes participant à l'assujettissement de vêtements. Des éléments comparables sont bien documentés dans divers ensembles culturels du midi de la France à partir du Néolithique moyen initial (escargotière de Villeneuve-Tolosane en Haute-Garonne) et dans divers ensembles chasséens qu'il s'agisse d'habitats (puits chasséen de Villeneuve-Tolosane ; Auriac à Carcassonne), voire de tombes (sépulture 13 de l'Agora de Cugnaux, Haute-Garonne).

Elles sont signalées aussi sous une forme plus souvent rectangulaire et sont parfois biforées dans les tombes de la culture catalane des Sepulcros de fosa, aussi bien dans les tombes en fosses- hypogées (Camí de Can Grau) que dans les sépultures en coffre du Solsonien : tombe de Pavia à Lloberola (Lerida), ou del Llord à Castellar de la Ribera (Lerida) signalées par A. M. Muñoz Amibilia (1965), ou la ciste 3 de la nécropole de la Feixa del Moro à Juberri en Andorre (Llovera, 1986 ; Llovera, Canturri, 1988). Dans 
ces contextes, elles sont souvent associées à des tombes féminines, mais pas exclusivement (sépulture CG 33 de Camí de Can Grau). Les exemplaires rectangulaires trouvés le plus souvent isolés ou par groupes de deux ont pu faire partie de colliers : l'un des deux exemplaires de la Feixa del Moro se trouvait sur le thorax, celui de la tombe 33 de Camí de Can Grau était placé entre les vertèbres cervicales, mais dans d'autres cas ces pièces ont été déposées à côté du corps et parfois associées à des poinçons.

Dans le cas de Coste Rouge, la possibilité de leur participation à une parure du cou ne repose que sur la présence de deux petits fragments près de l'épaule gauche à quelques centimètres de l'emplacement où ont été trouvés les dentales, auxquels l'un des pendentifs pouvait être associé. Toutefois, ces deux petits fragments étaient dans un secteur probablement remanié par un terrier. Les autres pièces, plus importantes et sans doute en place, étant éloignées du cou, ne peuvent être considérées de façon évidente comme appartenant à un collier. Il est manifeste que ce second groupe se composait de trois exemplaires jointifs. S'il s'agit bien d'éléments de parure rassemblant plusieurs objets identiques, on peut envisager, soit qu'ils formaient un dépôt séparé du corps, soit qu'ils étaient intégrés à une parure de tête éventuellement déplacée lors du mouvement du crâne au cours de la décomposition du corps. La morphologie pointue des deux parties distales les mieux conservées et le fait que les trois autres exemplaires aient été plaqués les uns contre les autres pourrait évoquer les ensembles à pointes plates assemblés par des ligatures, qui sont connus dans le Néolithique des lacs suisses où ils sont interprétés comme des peignes à carder, mais il s'agit, dans ces contextes, de pointes peu élaborées et non perforées. En tout état de cause, le caractère unique de cette disposition par groupe laisse le champ libre à plusieurs interprétations. Il convient de rappeler que ces types de pièces existent aussi dans des contextes plus récents, le type rectangulaire plat est présent dans quelques ensembles du Néolithique final et du Chalcolithique du Gard (Barge, 1982). Une large pièce arquée et pointue provenant de la grotte d'Arbolí à Reus (Tarragona en Catalogne) pourrait évoquer les pièces de Coste Rouge ; elle a été interprétée comme une aiguille et daterait de l'âge du Bronze (Vilaseca, 1973).

\section{L'ÉQUIPEMENT FUNÉRAIRE}

L'équipement funéraire est représenté par un dépôt de pièces lithiques et d'outils en os situé à gauche du corps dans le prolongement du membre supérieur gauche. Ce dépôt ne comporte évidemment que des objets aptes à se conserver, il faut noter que dans la même zone, on a pu observer une tache pulvérulente de matière noire, apparemment carbonisée, qui a été prélevée mais n'est pas encore analysée ; il pourrait s'agir du résidu d'un élément en matière organique.

\section{LES OBJETS LITHIQUES}

Le dépôt d'offrandes situé à quelques centimètres à l'est de l'emplacement qu'occupait la main gauche comportait trois éléments lithiques : une pointe de flèche à pédoncule et ailerons et deux lamelles de silex; il est probable que l'autre armature à pédoncule et ailerons retrouvée dans le comblement supérieur du coffre faisait partie du même ensemble (fig. 17, $\mathrm{n}^{\circ}$ 2). D'autres éléments lithiques très petits ou fragmentés qui ont été trouvés lors du tamisage à l'eau ou dans le remplissage supérieur du coffre sont probablement intrusifs. Il s'agit d'un casson, de quatre esquilles et de deux fragments de pièces débitées en silex. La première est un fragment mésial de lamelle en silex brûlé qui porte des retouches marginales semi-abruptes bilatérales, l'autre est une partie distale de lamelle en silex local patiné. On note aussi un petit débris de cristal de quartz hyalin automorphe.

\section{Les pointes de flèches}

Les pointes de flèches sont toutes les deux du type à pédoncule et ailerons récurrents (fig. $17, \mathrm{n}^{\text {os }} 1$ et 2 ). La première, trouvée dans la partie supérieure du remplissage du coffre à proximité de deux dentales, est probablement un élément remonté par un terrier. Elle est en silex blond patiné par un voile blanchâtre. L'aspect gras et luisant indique un traitement thermique qui a fait ressortir quelques ponctuations rouges d'oxydes métalliques. Le support ne peut être déterminé étant donné le caractère très réduit de la réserve non retouchée observable sur la face inverse ; compte tenu de la largeur de la pièce, il s'agit probablement d'un éclat. La partie apicale présente des côtés concaves ; elle est entièrement façonnée par retouches couvrantes bifaciales rasantes, de type subparallèle, faites par pression avec une régularisation ultérieure par retouches marginales. Le pédoncule et les encoches dégageant les ailerons ont été réalisés par retouches obliques, elles aussi obtenues par pression. Il s'agit d'une pièce quasi intacte qui ne présente qu'une minuscule fracture à l'extrémité de l'aileron gauche (fig. 17, no 1). La seconde est légèrement asymétrique. Elle 

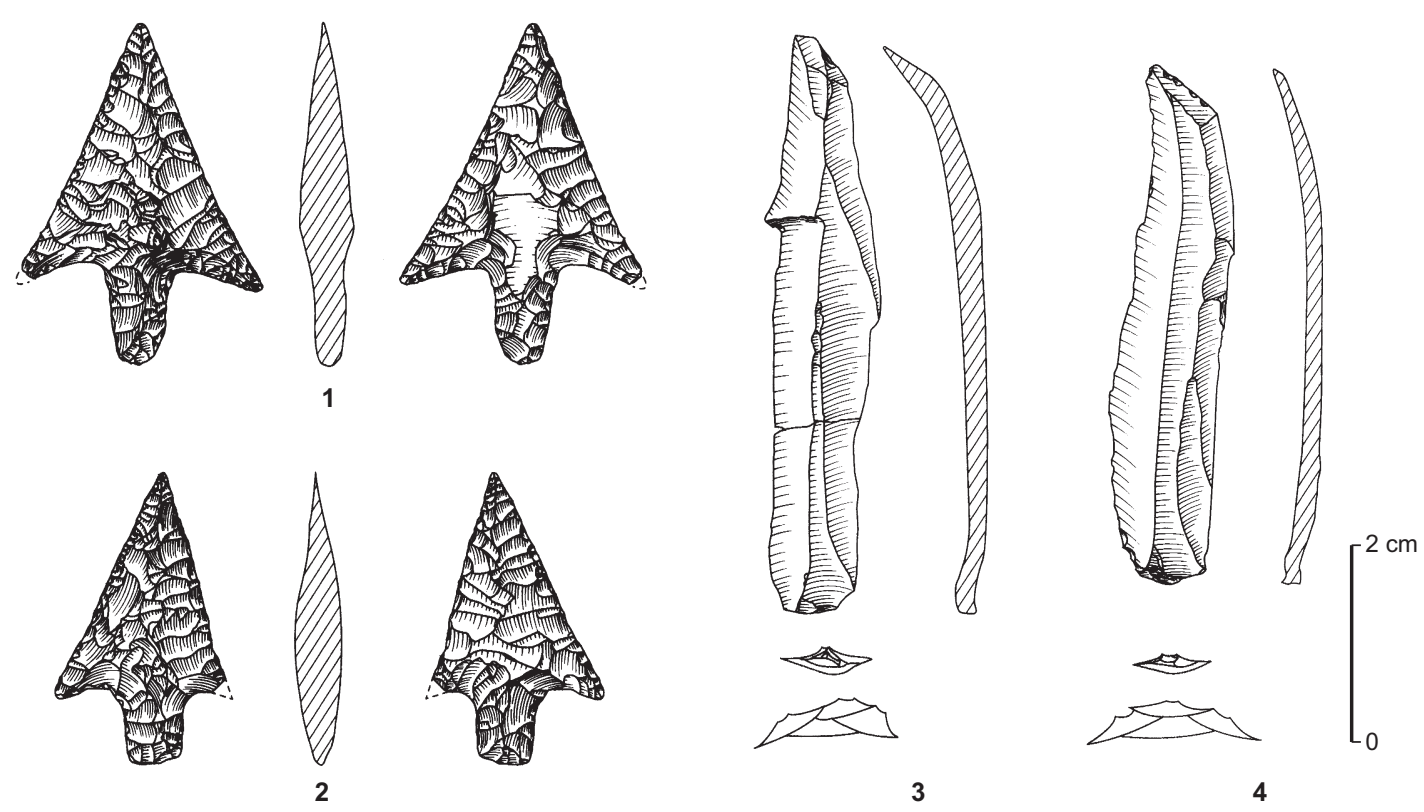

Fig. 17 - Tombe de Coste Rouge à Beaufort (Hérault). Industrie lithique en silex bédoulien : 1, 2, pointes de flèches ; 3, 4, lamelles brutes (DAO : M. Gandelin et R. Marsac, ATA).

est en silex blond qui a pris une teinte légèrement rosée à la suite du traitement thermique qui lui confère un aspect gras et luisant et a fait ressortir de multiples ponctuations rouges d'oxydes minéraux, ce qui indique une probable appartenance du matériau au groupe des silex bédouliens du Vaucluse. La partie apicale, triangulaire, est entièrement façonnée par retouches couvrantes bifaciales subparallèles réalisées par pression. Le pédoncule et les encoches dégageant les ailerons ont été obtenus par retouches obliques, la base du pédoncule équarri est amincie. Cette pièce ne présente qu'une petite fracture ayant enlevé l'extrémité de l'aileron droit (fig. 17, no 2).

Ces deux armatures appartiennent au même type, qui est généralement considéré comme caractéristique du début des âges des Métaux. Plusieurs séquences richement documentées du domaine nord-alpin ont montré un développement de ce type au Néolithique final de style Auvernier, comme à Yverdon (Uerpmann, 1977), et surtout au Cordé (Jeunesse et al., 1998) ou au Campaniforme comme à Chalain (Saintot, 1998).

Dans le midi de la France, bien que l'on connaisse quelques armatures à pédoncule et ailerons droits, le plus souvent à retouches partielles dans le Chasséen (Courtin, 1974; Costantini, 1984), le type à ailerons récurrents et retouches bifaciales couvrantes est généralement considéré comme exclusivement chalcolithique et plus spécifique- ment attribué au complexe campaniforme ou à ses horizons dérivés, datés du Bronze ancien (Guilaine, 1967 ; Gutherz, Hugues, 1980; Sauzade, 1983). C'est sur la foi de ces arguments que la sépulture de Coste Rouge a été considérée dans un premier temps comme campaniforme, mais il faut reconnaître que l'examen d'autres contextes permet de réviser cette attribution. En Languedoc même, le fossé de Roc d'en Gabit à Carcassonne a livré un exemplaire absolument typique en contexte vérazien, d'autres sont signalés dans le Néolithique final de la structure 35 de Roquemengarde à Saint-Pons-de-Mauchiens (Hérault), voire même dans le Chasséen récent de la couche 8 de Font-Juvénal à Conques-sur-Orbiel dans l'Aude (Briois, 1997). En Provence, quelques-unes ont été signalées sur des stations de plein air chasséennes, comme celles de Tusèle à Cabasse (Var), mais on en trouve aussi dans des ensembles chasséens stratifiés plus probants, comme celui de la grotte de l'Église supérieure à Baudinard-sur-Verdon (Var) où un exemplaire est signalé dans la couche 6 (Gassin, 1996). En Italie, ce type d'armature a pu apparaître de façon plus précoce; il est signalé dans les registres de mobilier des cultures de Ripoli (Cremonesi et al., 1998) ou dans la phase moyenne de la culture des Vases à bouche carrée comme à Gaione, Catena (Parma) (Bernabó Brea et al., 1990). Il en est de même en Catalogne où plusieurs ensembles funéraires clairement attribuables au Néolithique moyen ont 
livré des exemplaires morphologiquement très proches de ceux de Coste Rouge. On peut citer notamment celles de la tombe en fosse de la Bóvila d'en Joca de Montornès, des tombes 30, 33 et 39 de la Bóvila Madurell dans le Vallès, celle de la tombe de la Bóvila Pinell près de Gérone (Muñoz Amibilia, 1965) ou celles des tombes-hypogées de la fin du Néolithique moyen de la nécropole de Camí de Can Grau à la Roca del Vallès. Sur ce dernier site, plusieurs tombes ont livré des flèches pédonculées dont une à ailerons récurrents dans la tombe 42 (Marti i Rossell et al., 1997). On peut donc retenir que ce type de flèche peut exister dans des ensembles funéraires du Néolithique moyen pyrénéen. D’ailleurs, il n'est pas exclu qu'il soit attesté dans des ensembles funéraires de cette période fouillés sur le versant nord de la chaîne. Ce pourrait être le cas notamment de la sépulture de la grotte 4 de las Claouzos à Auriac (Aude), qui a livré une armature semblable à celles de Coste Rouge au sein d'un mobilier funéraire dont les affinités avec les Sepulcros de fosa ont déjà été soulignées (Chantret et al., 1970).

\section{Les lamelles}

Les lamelles sont représentées par deux exemplaires; l'une, entière, apparaissait par sa face inverse $\left(n^{\circ} 78\right)$ et l'autre était cassée en deux morceaux: le fragment distal ( $\left.n^{\circ} 50\right)$ était de chant et le fragment proximal apparaissait par sa face inverse $\left(n^{\circ} 79\right)$. Ces deux fragments étaient peu éloignés $(2 \mathrm{~cm})$, mais avec des orientations incompatibles pour envisager une fragmentation postdépositionnelle. En effet, les deux parties qui se raccordent sont séparées par $6 \mathrm{~cm}$ de part et d'autre du poinçon $\mathrm{n}^{\circ} 1$ (fig. $18, \mathrm{n}^{\text {os }} 6$ a et $6 \mathrm{~b}$ ). Il semble donc plus logique de considérer qu'il s'agit d'une pièce cassée avant le dépôt, soit au moment du débitage (accident fréquent), soit après et qu'elle aurait ensuite été déposée en deux morceaux. Ces deux lamelles sont en silex gris-blond translucide, avec une zone opaque grise ou légèrement rubanée qui est due à des impuretés de zone souscorticale dans leur partie distale; il s'agit probablement de silex bédoulien du Vaucluse. Il faut noter que la zonation des impuretés et l'orientation des rubans vue en transparence a un aspect tout à fait identique sur les deux pièces qui proviennent assurément du même flanc gauche d'un nucléus. Il n'a pas été possible toutefois de les raccorder, ce qui indique qu'elles proviennent sans doute de séries différentes détachées dans la même zone du nucléus, comme le suggère en outre leur différence de longueur. Les zones bien silicifiées ont un aspect luisant mais qui n'est pas assez prononcé pour affirmer un traitement thermique du silex.
Il s'agit de lamelles de plein débitage à extrémité distale aiguë et arquée, voire légèrement outrepassée pour la première (fig. 17, no 3 ). Les talons sont peu épais et ont été facettés à partir de la corniche vers le plan de pression, ce qui détermine un épaulement haut. Ils sont centrés, avec un angle d'éclatement orthogonal et un bulbe bien marqué en position haute. Le profil de ces lamelles est plat dans les deux tiers proximaux médians et incurvé en zone distale. Tous ces caractères suggèrent un débitage par pression sur nucléus conique ou semiconique, même si ces lamelles ne sont pas d'une régularité parfaite (Binder, 1984). Le rythme de débitage, défini d'après l'observation des lancettes, est de type 1-2-3 dans la partie mésiale de l'exemplaire 1 qui porte le négatif d'un enlèvement formant un ressaut sur le côté gauche. L'autre lamelle est de code 2-1-2' mais il se pourrait que cela soit dû à l'enlèvement d'une microlamelle de recintrage sur le latéral droit.

L'examen de ces lamelles en microscopie optique a été réalisé par S. Philibert qui n'a relevé aucun indice tracéologique hormis de rares microébréchures qui ne sont pas d'origine fonctionnelle. Il s'agit donc probablement de pièces brutes sélectionnées dans une production qui a dû être faite au moment de la sépulture et au moins en partie pour effectuer l'offrande. Cette constatation rejoint celles effectuées dans la nécropole de la Bóvila Madurell en Catalogne où, dans la sépulture B6, un dépôt comportait huit lamelles brutes qui se raccordent, ce qui indique une production destinée essentiellement à des fins funéraires. Dans la même nécropole, il a d'autre part été observé que les lamelles associées aux enfants n'avaient pas été utilisées, tandis que celles associées aux adultes étaient généralement usées (Gibaja Bao, Clemente Conte, 1996).

La nature du silex utilisé, probablement du silex blond bédoulien importé de Provence occidentale, et les caractères technologiques évoquent le technocomplexe du Chasséen méridional, même si elles ne sont pas des plus typiques en raison de leur faible régularité et de l'absence du traitement thermique. Le fait que ces lamelles aient été détachées d'un nucléus conique ou semi-conique pourrait plus particulièrement correspondre au Chasséen ancien (Binder, 1991), mais c'est une considération qui ne peut être tenue pour certaine dans la mesure où l'on sait que de telles modalités de mise en forme des nucléus peuvent perdurer au Chasséen récent. On connaît aussi ce type de nucléus en silex blond non chauffé dans des horizons culturels du Néolithique récent ou final en particulier sur le site de Mourral à Trèbes en contexte vérazien ancien. 


\section{LES POINÇONS EN OS}

Le dépôt situé à gauche du corps au niveau du bassin et près de l'emplacement de la main gauche comportait les restes de quatre poinçons mal conservés; aucun n'est réellement complet. Ils se composent de fragments dont certains, fortement concrétionnés par du calcin, ont résisté à la dissolution mais se désagrègent en lamines, et d'autres, à la surface d'aspect vermiculé, ont subi une forte attaque chimique due aux racines. L'individualisation de ces pièces et leur description est fondée d'abord sur les restes prélevés puis sur leur position enregistrée par dessin et photographie. Il ressort de l'examen de ces données que ces quatre poinçons étaient disposés plus ou moins en faisceau avec leurs pointes dirigées vers le nord (fig. $18 \mathrm{n}^{\text {os }} 1-4$ ).

Le poinçon $n^{\circ} 1$, le plus élevé, apparaissait par sa surface supérieure. C'est le mieux conservé ; il se compose de cinq fragments dont trois se raccordent, malgré leur forte altération, pour former la base de l'outil (fig. 19, $\mathrm{n}^{\mathrm{o}} 1$ ). Il se réduit donc à trois tronçons dont le mieux conservé est la pointe qui présente une fissure ancienne concrétionnée. La fragmentation et les lacunes sont très probablement liées à des phénomènes postdépositionnels. Il s'agit d'un poinçon long sur demi-métapode de ruminant, à poulie probablement non façonnée. L'origine anatomique précise et spécifique du support est cependant difficile à déterminer. La longueur des pièces mesurées in situ est de $13,5 \mathrm{~cm}$. Cela suggère qu'il s'agit d'un capriné ou d'un chevreuil. Étant donné l'état des surfaces osseuses, les observations technologiques ne peuvent qu'être incertaines. La longueur de la pièce et le fait que la pointe soit légèrement courbée vers l'extérieur de l'os indiquent que ce poinçon a été réalisé en prenant en compte un morceau de la partie proximale du métapode. L'utilisation de la quasi-totalité de la longueur de ce dernier implique un mode de partition par rainurage ou abrasion. Le mode de façonnage est l'abrasion, comme le révèlent la section convexe des bords non altérés sur le fût et la pointe qui est effilée et légèrement asymétrique.

Le poinçon $n^{\circ} 2$ est représenté par trois fragments, dont deux se raccordent pour former la pointe, le troisième étant une poulie fortement altérée (fig. 19, no 2). Ces éléments apparaissaient sur leur face supérieure et se trouvaient exactement dans le même axe, ce qui accrédite leur appartenance à la même pièce dont le fût a totalement disparu. La longueur mesurée in situ est de 13,5 cm entre les deux extrémités. Par ailleurs, la direction de la poulie est parallèle à l'axe du fût. Le support pourrait donc être un métapode de petit ruminant (mouton ou chevreuil).

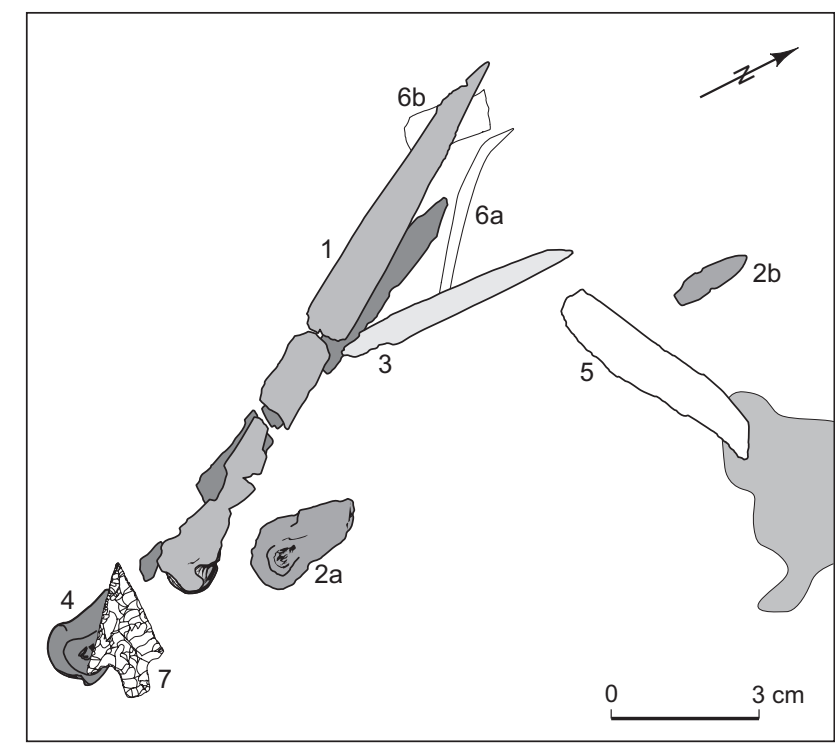

Fig. 18 - Tombe de Coste Rouge à Beaufort (Hérault). Détail du dépôt d'outils en silex et en os : 1 à 4, poinçons; 5, 6a, 6b, lamelles en silex; 7, pointe de flèche en silex (DAO: M. Gandelin).

Il s'agit donc probablement d'un long poinçon sur demimétapode à poulie non façonnée. La pointe est mal conservée, elle semble avoir été d'axe, courte et d'aspect ogival.

Le troisième poinçon n'est représenté que par un fragment de fût étroit qui apparaissait par son côté droit (fig. 19, $\mathrm{n}^{\mathrm{o}}$ 3). Il présente deux fissures transversales anciennes consolidées par le calcin. Les surfaces sont desquamées ou vermiculées, ce qui empêche toute observation d'ordre technologique. La section elliptique dans ce secteur suggère toutefois un façonnage en abrasion.

Le quatrième poinçon se trouvait sous le premier et apparaissait lui aussi par sa face supérieure. Il se compose de sept fragments, pour la plupart érodés, qui n'ont pas pu être raccordés (fig. 19, $\mathrm{n}^{\mathrm{O}} 4$ ). La longueur mesurée in situ est, elle aussi de $13,5 \mathrm{~cm}$. Ces éléments se trouvaient plus ou moins dans le même axe, ce qui suggère que la fragmentation et les lacunes sont dues à des phénomènes postdépositionnels. Le support semble être un métacarpien de mouton ou de chevreuil (poulie parallèle à l'axe du métapode, ce qui semble exclure la chèvre, chez qui elle est oblique). Le fait que la pointe se relève implique que la quasi-totalité du métapode est représentée, ce qui indique un mode de partition excluant la percussion (rainurage ou abrasion). Il s'agit d'un poinçon long à poulie conservée brute, probablement façonné par abrasion. La pointe devait être d'axe, dégagée du fût, de forme triangulaire et à côtés 


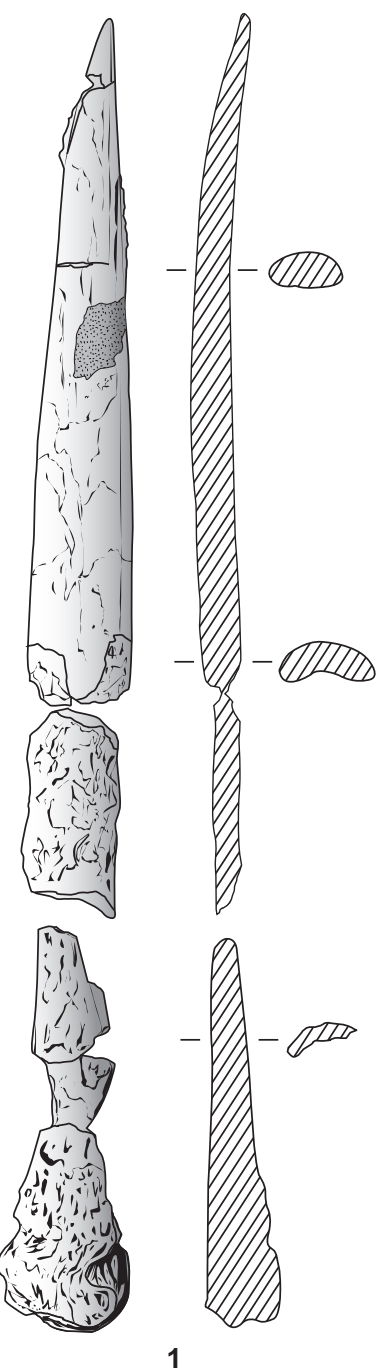

1

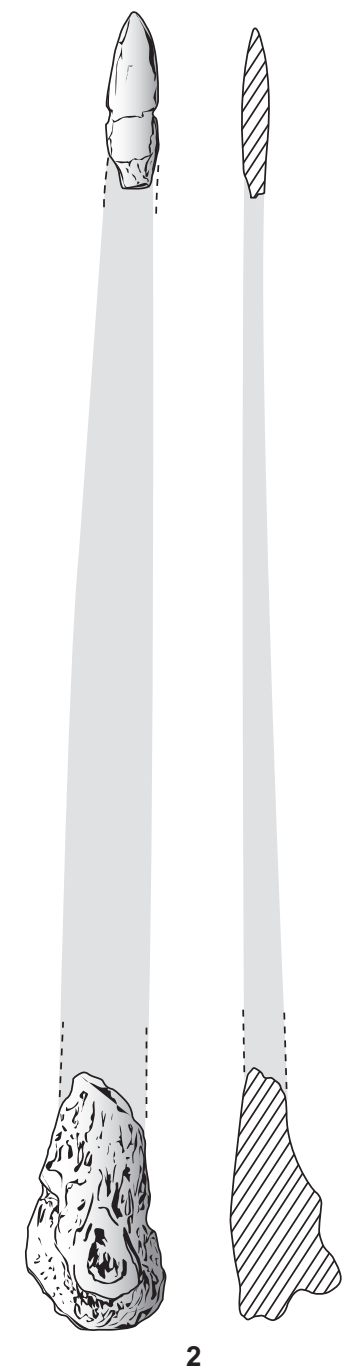

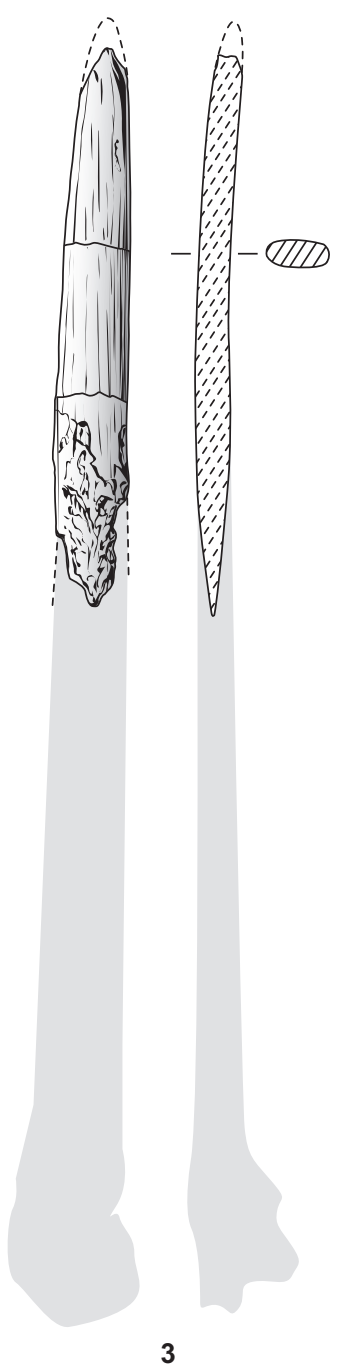

Fig. 19 - Tombe de Coste Rouge à Beaufort (Hérault).

Fragments de poinçons sur métapodes de caprinés et proposition de restitution (DAO : M. Gandelin et R. Marsac, ATA).

concaves, particularité parfois interprétée comme résultant d'un travail de vannerie (Camps Fabrer, 1993).

Les poinçons déposés dans la tombe forment, au moins pour trois d'entre eux, un groupe homogène de longs poinçons à poulie conservée réalisés à partir de métapodes de petits ruminants. Les quatre poinçons proviennent au moins de trois os distincts, mais pourraient renvoyer au même animal. La longueur des pièces implique un mode de partition lent, par abrasion ou par rainurage, et un mode de façonnage par abrasion ; il s'agirait donc de pièces résultant d'un travail long et soigné. Toutefois l'état de conservation très mauvais ne permet pas de vérifier cette hypothèse (pas de possibilité d'observation de traces de façonnage), ni de l'infirmer (impossibilité de voir des traces d'utilisation).
Si les poinçons de ce type existent dans de nombreux groupes culturels, il faut toutefois noter qu'ils figurent au premier rang des outillages en os du Chasséen méridional et des groupes apparentés, qu'il s'agisse du Chasséen septentrional (Sénépart, Sidéra, 1991) ou de la culture catalane des Sepulcros de fosa (Martín Cólliga, Villalba Ibañez, 1999). Dans ces trois entités culturelles, les poinçons longs sur métapodes de caprinés ou de cervidés figurent régulièrement au sein des équipements funéraires des sujets adultes des deux sexes (Vaquer, 1998 ; Sidéra, 2000 ; Muñoz Amibilia, 1965). Ils peuvent figurer au sein d'offrandes variées et parfois constituer des lots de plusieurs exemplaires disposés en faisceaux : 7 poinçons dans la sépulture 13 de l'Agora de Cugnaux en Haute-Garonne, 9 poinçons dans 
la tombe I de Boury-en-Vexin dans l'Oise, et même jusqu'à 60 dans la sépulture 2 de la nécropole del Llord à Castellar de la Ribera, Lérida (Muñoz Amibilia, 1965)

\section{LES RESTES DE FAUNE}

Hormis deux vertèbres de microfaune et neuf esquilles d'os brûlés trouvées dans le remplissage supérieur du coffre, les restes de faune comportent treize éléments clairement associés à la sépulture et qui ont été identifiés (fig. 20).

\section{BOVIN (BOS TAURUS)}

Un radius gauche d'un individu périnatal dont il ne reste que la diaphyse (fig. 20, n 3). Les épiphyses, qui n'étaient pas soudées, sont absentes. Rappelons que ce type d'os sans épiphyse est le support habituel de petites idoles obtenues par des dessins gravés, incrustés ou peints dans des contextes culturels divers, par exemple du Néolithique danubien : tombe 586 de la nécropole du Vieux Tordoir à Berry-au-Bac dans l'Aisne (Sidéra, 2000) ou idoles du Chalcolithique ancien du Sud-Est ibérique (Mariën, Ulrix-Closset, 1985). Des restes analogues, mais sans aucun signe visible, figurent parmi les offrandes dans certaines tombes de la nécropole de Camí de Can Grau en Catalogne (Martinez Moreno, 1997) qui est contemporaine du Chasséen récent. La tombe CCG 21 notamment, qui contenait un enfant d'environ trois ans, recelait elle aussi un radius de jeune veau, localisé sous l'épaule gauche $\mathrm{du}$ sujet, ainsi que la tombe CCG 42 qui contenait un individu de sexe masculin, et où l'os de veau était dans la même position.

\section{CAPRINÉS (OVIS ARIES VEL CAPRA HIRCUS)}

Une phalange proximale dont l'épiphyse proximale est soudée : âge supérieur à 7-10 mois (fig. 20, n 4).

Une phalange proximale de jeune individu dont l'épiphyse proximale est non soudée et absente : âge inférieur à 7-10 mois (fig. 20, $\mathrm{n}^{\circ} 13$ ).

Une phalange proximale dont l'épiphyse proximale est en cours de fusion : âge autour de 7-10 mois (fig. 20, $\mathrm{n}^{\circ} 8$ ).

La partie distale d'un radius droit dont l'épiphyse non soudée est absente; il s'agit vraisemblablement d'un nouveau-né, étant donné la taille et la texture de l'os (fig. 20, $\mathrm{n}^{\circ} 1$ ).

\section{OURS BRUN (URSUS ARCTOS)}

Une phalange proximale du doigt postérieur IV G est attribuée à cette espèce (fig. 20, n 2).

\section{CANidés (CANIS VEL VULPES)}

Un fragment distal de phalange qui est de petite taille (fig. 20, $\left.\mathrm{n}^{\circ} 10\right)$.

Un métatarsien II droit de canidé de la taille d'un chien (Canis familiaris) qui présente une épiphyse distale soudée : âge supérieur à 8 mois environ (fig. 20, n 7).

Un métacarpien III droit de canidé à épiphyse distale soudée qui est de petite taille: âge supérieur à 8 mois environ (fig. 20, $\mathrm{n}^{\circ} 6$ ).

Une phalange proximale de petite taille qui présente une épiphyse proximale soudée: âge supérieur à 7 mois (fig. 20, $\mathrm{n}^{\circ} 12$ ).

Une phalange proximale de petite taille qui présente une épiphyse proximale soudée: âge supérieur à 7 mois (fig. 20, $\mathrm{n}^{\circ} 11$ ).

Une phalange proximale de petite taille qui présente une épiphyse proximale soudée: âge supérieur à 7 mois (fig. 20, nº 9).

Il est à noter, au sujet des canidés, que la tombe 45 de Camí de Can Grau contenait une mandibule de chien et un squelette de renard, ce qui offre un nouveau parallèle avec la sépulture de Coste Rouge.

\section{CARNIVORE INDÉTERMINÉ}

Une extrémité distale de métapode qui est de petite taille (fig. 20, $\mathrm{n}^{\circ} 10$ ).

Il semble important de noter que ces restes de faune appartiennent, pour la plupart, à des individus distincts (un bovin, deux, voire trois caprinés, un ours et, vraisemblablement, deux canidés différents), représentés chacun par très peu d'éléments, sans connexions apparentes (sauf peutêtre pour les $n^{\text {os }} 102$ et 103 trouvés ensemble au-dessous du poignet droit et qui correspondent à un métacarpien III droit et à une phalange proximale). La nature des os et leur bon état permettent d'évacuer l'hypothèse de dépôts d'offrande carnée, il s'agit plus probablement d'un dépôt symbolique. Hormis les deux os de petit canidé trouvés sous le poignet droit, les autres restes se trouvaient à proximité 


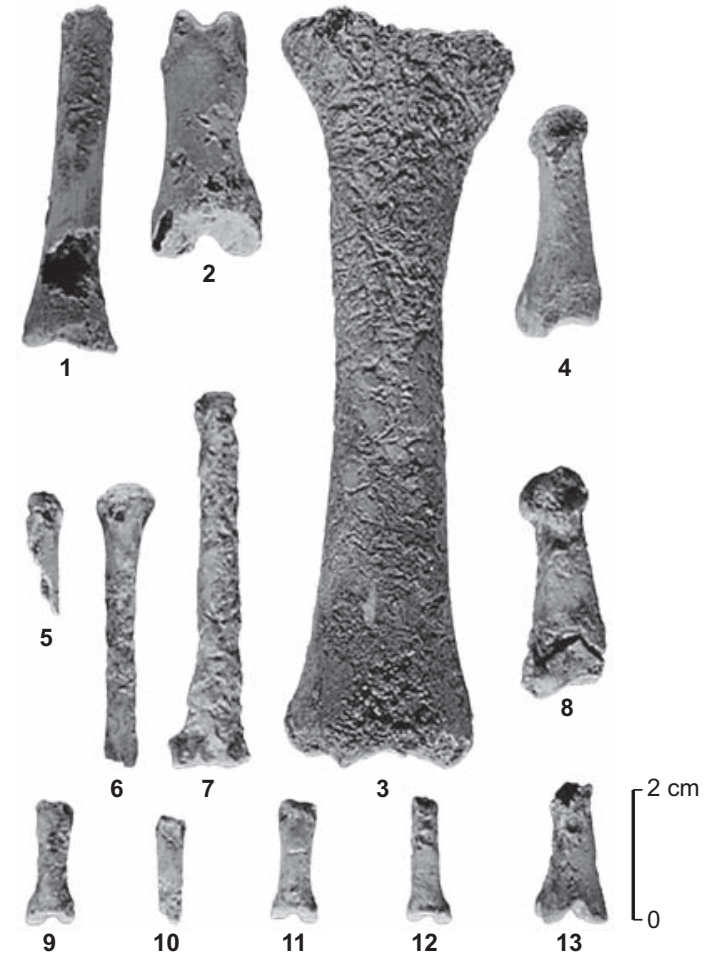

Fig. 20 - Tombe de Coste Rouge à Beaufort (Hérault). Os de faune faisant partie de la dotation funéraire (cliché: J. Vaquer, CNRS).

du thorax et du bras gauche, la plupart étaient mêlés aux éléments de parure en dentales. On note que certains os (le radius de bovin, les deux phalanges de caprinés) se trouvaient au-dessus de l'humérus; la phalange d'ours et celle de canidé étaient coincées sous l'humérus et en contact avec le gril costal ; enfin, une phalange de canidé se trouvait sous la scapula gauche. Il n'est donc pas impossible que ces divers éléments de faune aient fait partie d'un ensemble porté en guise d'amulettes ou de fétiches, voire qu'ils aient été intégrés, au moins pour certains d'entre eux, à l'élément orné de dentales.

On rappellera à ce sujet que de tel dépôts de restes de faune isolés sont attestés dans d'autres ensembles funéraires, comme une phalange de capriné dans la tombe chasséenne 37 des Plots de Berriac (Aude) ou un radius de bovin immature sans épiphyse dans les tombes CCG 21 et CCG 42 de la nécropole de Camí de Can Grau à Roca del Vallès (Barcelone), dans les deux cas au niveau de l'épaule. L'aspect rituel de ce dépôt d'os de faune est souligné par Martinez Moreno (1997), de même que des dépôts d'os de suidés, de chien et de renard parfois en connexion dans la même nécropole. Ces restes de faune peuvent aussi correspondre à l'évocation symbolique d'un bestiaire d'accompa- gnement du mort selon le principe de la synecdoque, une partie valant pour le tout, ce qui équivaudrait à représenter symboliquement chaque animal par une partie le constituant. L'évocation de ce bestiaire serait dans ce cas orientée vers les activités d'élevage : ovins et bovins, ainsi que chiens, pour assurer leur protection contre leurs prédateurs: canidés sauvages et ours.

\section{LES RESTES CARPOLOGIQUES}

Le remplissage en place de la tombe a été intégralement tamisé à l'eau avec des cribles à $1,5 \mathrm{~mm}$, ce qui a permis de récupérer quelques restes carpologiques carbonisés qui ont été déterminés par P. Marinval. Il s'agit de graines de céréales représentées par Hordeum vulg. var. nudum (1 caryopse), Triticum dicoccum (2 caryopses), Triticum aestivo compactum (2 caryopses), Triticum sp. (1 caryopse) et Cerealia (13 éléments). Il nous paraît difficile d'envisager que ces éléments fassent partie d'un dépôt intentionnel; ils ont d'ailleurs été trouvés dans le comblement terreux de la tombe. Ce dernier a dû se mettre en place assez rapidement après la condamnation de la tombe ; on peut donc considérer qu'il s'agit probablement de graines carbonisées préhistoriques qui ont été introduites par des facteurs naturels (infiltrations) peu de temps après l'inhumation ou à l'occasion de perturbations plus récentes par des terriers d'animaux fouisseurs, dont l'action sur le remplissage de la tombe est prouvée par des indices de remaniements.

$$
*
$$

La fouille de la tombe de Coste Rouge à Beaufort renouvelle sensiblement la question des tombes à appareillage lithique de la Préhistoire récente qui sont attestées en Languedoc occidental. Il semble acquis, au vu des affinités architecturales avec le Solsonien, et en raison des similitudes concernant le mobilier funéraire qui renvoient explicitement au Chasséen et à la culture catalane des Sepulcros de fosa, que cette tombe peut être située à la fin du Néolithique moyen ou à la transition avec le Néolithique final, soit vers la fin de la première moitié du IVe millénaire avant notre ère.

Les seuls éléments qui pourraient être invoqués pour envisager une datation plus récente sont les armatures à pédoncule et ailerons récurrents à retouches bifaciales et la position du sujet couché sur le dos. On a vu cependant que ce type d'armature de flèche, courant au Chalcolithique, est en fait attesté de façon indéniable dans plusieurs ensembles de la culture des Sepulcros de fosa. La position couchée sur le 
dos est rarement mentionnée dans les tombes en coffre du Solsonien ou du Chasséen, dans lesquelles les sujets sont le plus souvent déposés en position repliée ou contractée. Cet argument ne peut cependant être considéré comme rédhibitoire dans la mesure où cette position a été signalée dans certaines tombes en coffre néolithiques locales, comme celle de Lapierre à Castelnaudary (Aude) publiée anciennement par A. Fages (1923). Par ailleurs, cette position est largement avérée dans les tombes hypogées de type $5 \mathrm{~b}$, c'est-à-dire les plus récentes de la zone du Vallès en Catalogne, en particulier dans les nécropoles de Camí de Can Grau et de la Bóvila Madurell où ce type est daté par le ${ }^{14} \mathrm{C}$ (tombe $7.7:$ UBAR $445: 4880 \pm 173 \mathrm{BP}$, soit 3905-3385 av. J.-C.).

Pour mieux asseoir cette interprétation d'attribution chronologique et culturelle, une datation radiométrique AMS sur un échantillon tiré de l'humérus gauche du sujet de Coste Rouge a été réalisée dans le cadre du programme d'action collective de recherche intitulée «Espaces et expressions funéraires au Néolithique moyen dans le monde pyrénéen et ses marges ». Le résultat obtenu est tout à fait conforme à l'interprétation formulée d'après les critères architecturaux et le mobilier :

ERL 9626 : $4743 \pm 46$ BP, soit 3638-3377 av. J.-C. à deux écarts types avec 68,9\% de probabilité entre 3638-3497 av. J.-C. et $25 \%$ de probabilité entre 3456-3377 av. J.-C.

Dans la région considérée, la plage de temps incluse dans la probabilité à deux écarts types qui va du $37^{\mathrm{e}}$ au $34^{\mathrm{e}}$ siècle se situe à cheval sur la fin du Chasséen et le début du Saint-Ponien. Toutefois, les pics de probabilité maximale sont concentrés sur la fin du $37^{\mathrm{e}}$ siècle et le $36^{\mathrm{e}}$ siècle av. J.-C., période qui correspond plutôt à la fin du Chasséen. Cette plage chronologique est la même que celle de la tombe en « chambre » de Costa dels Garrics del Caballol II à Pinell dans le Solsonès en Catalogne (Castany, 1990), qui ressemble beaucoup à celle de Coste Rouge (CG 2 : UBAR 209 : $4860 \pm 90$ soit 3950-3350 av. J.-C.), hormis le fait qu'elle a reçu quatre inhumations.

D'après ces jalons, il semble donc que ce type de tombe «en chambre " à fermeture frontale et vestibule ou puits soit attesté des deux côtés des Pyrénées à la même période. C'est un type assez fréquent en Catalogne où il existe à la fois sous des formes plus ou moins enterrées, mais aussi hors sol et même au sein de tumulus. La tombe de Coste Rouge est le seul exemplaire situé en zone nord-pyrénéenne pour lequel on peut affirmer une position souterraine dans une fosse comportant un dégagement formant un vestibulepuits. Le niveau de circulation néolithique étant détruit, on ne peut pas savoir si cette tombe avait en surface un dispositif de signalisation ou si elle était recouverte par un tumulus.

Dans la mesure où ce type présente des caractères hybrides (dimensions intermédiaires entre les petites cistes individuelles et les dolmens, mise en œuvre de dalles pouvant atteindre plusieurs quintaux mais de poids inférieur à la tonne, accès frontal avec de fines dalles potentiellement amovibles autorisant une utilisation multiple, insertion dans des fosses mais aussi au sein de tertres), ces chambres sont considérées en Catalogne comme des tombes submégalithiques. Pour certains auteurs elles pourraient être un type influencé par la civilisation mégalithique pyrénéenne contemporaine qui débuterait au $V^{\mathrm{e}}$ millénaire, si l'on retient comme valable les datations hautes obtenues pour quelques dolmens à couloir de l'Empordà à Girona, Catalogne (Tarrus, 1987). D'autres auteurs privilégient les aspects techniques qui auraient conduit à dresser d'abord les trois principaux orthostates, puis à placer les dalles de couverture sur trois points d'appui. Ce mode de construction serait lié aux tombes les plus grandes du groupe de Solsona dont les dalles de couverture sont trop lourdes pour pouvoir être manœuvrées aisément au moment de l'inhumation. Leur condamnation par une dalle frontale en appui sur la couverture serait plus pratique que ce soit pour une seule inhumation ou pour plusieurs de façon successive (Cura Morera, 1992). Quel que soit le point de vue, il faut reconnaître que les cas documentés de chambre avec accès frontal qui ont reçu des sépultures plurielles ou qui ont fait l'objet de réutilisations font figure d'intermédiaires entre les tombes généralement individuelles du Néolithique moyen et les tombes collectives du Néolithique final.

Il semble en effet que la question centrale posée par ce type de tombe n'est pas tellement liée à l'existence d'une fermeture frontale, mais plutôt à l'utilisation plurielle permise par cette fermeture amovible, ainsi que par la conception générale des constructions hors sol permettant sa réouverture (signalisation du vestibule-puits à la surface du sol ou du tertre). La taille de la chambre est sans doute aussi un critère important; en effet, on peut imaginer que les petits coffres non mégalithiques aient pu être rouverts par le haut pour une utilisation plurielle, tandis que les plus grandes chambres avec des dalles de couverture de plusieurs centaines de kilogrammes auraient été plus facilement réutilisables par un accès frontal. Ces deux paramètres (identification d'un accès horizontal pour des réutilisations et grande taille de la chambre) sont évidemment très proches des critères définissant les dolmens. Ces 
monuments étaient, quant à eux, conçus dès le départ pour une utilisation durable et collective. Ils étaient donc réalisés hors sol avec des tumulus comportant un accès clairement identifiable et une chambre véritablement mégalithique nécessitant pour sa construction une force de travail supérieure à celle d'une famille nucléaire. Dans ces conditions, il semble légitime de s'interroger sur la valeur phylétique des tombes semblables à celle de Coste Rouge dans le domaine pyrénéen. Il faut aussi chercher à savoir si cette évolution des architectures funéraires a été régie par des processus semblables en Languedoc et en Catalogne, ou bien par des interactions ou des influences entre les deux versants de la chaîne pyrénéenne au cours du Néolithique moyen et récent.

Dans le contexte actuel des connaissances, il subsiste trop d'inconnues ou de manques de précision pour restituer concrètement toute la trame des manifestations funéraires entre l'Èbre et l'Hérault au cours du Néolithique moyen récent (4700-3500 av. J.-C.). D'autre part, il existe une très grande disproportion documentaire entre les deux versants pyrénéens; en effet, l'état des connaissances sur le thème des architectures et des pratiques funéraires est fortement documenté en Catalogne, tandis qu'il est plutôt lacunaire dans le sud de la France. Si l'on se cantonne aux tombes à appareillage de dalles, on peut faire état de quinze sites dans la zone nord-orientale des Pyrénées. Puisque quelques sites sont de petites nécropoles, on peut compter une quarantaine de tombes mais peu parmi elles peuvent vraiment être analysées en détail, en raison d'une mauvaise conservation et aussi de l'ancienneté ou des déficiences des méthodes de fouilles.

Le réexamen de cette documentation, couplé à des vérifications sur les sites, lorsque cela était possible, a été amorcé dans le cadre de l'ACR «Espace et expressions funéraires au Néolithique moyen dans le monde pyrénéen et ses marges ». Il apparaît qu'au sein de ce corpus, somme toute réduit, il existe une assez forte variabilité des types de tombes (fig. 21). Des petites cistes avec un seul individu en position contractée sont attestées, l'une des mieux documentées étant celle de Labau à Ladern-sur-Lauquet dans l'Aude (Fages, 1930). Des coffres légèrement plus grands à sépultures doubles peuvent être cités, notamment ceux de Dela Laïga ou celui de Las Faïchos à Cournanel dans l'Aude (Guilaine, 1962 et 1996). Sur ces sites on ignore toutefois la position des tombes par rapport au niveau de circulation de l'époque, voire l'existence ou l'absence de tertres. Pour ces aspects, il faut se tourner vers la seule nécropole fouillée in extenso, celle de Camp del Ginebre à Caramany dans les Pyrénées-Orientales. Sur ce site on constate la coexistence

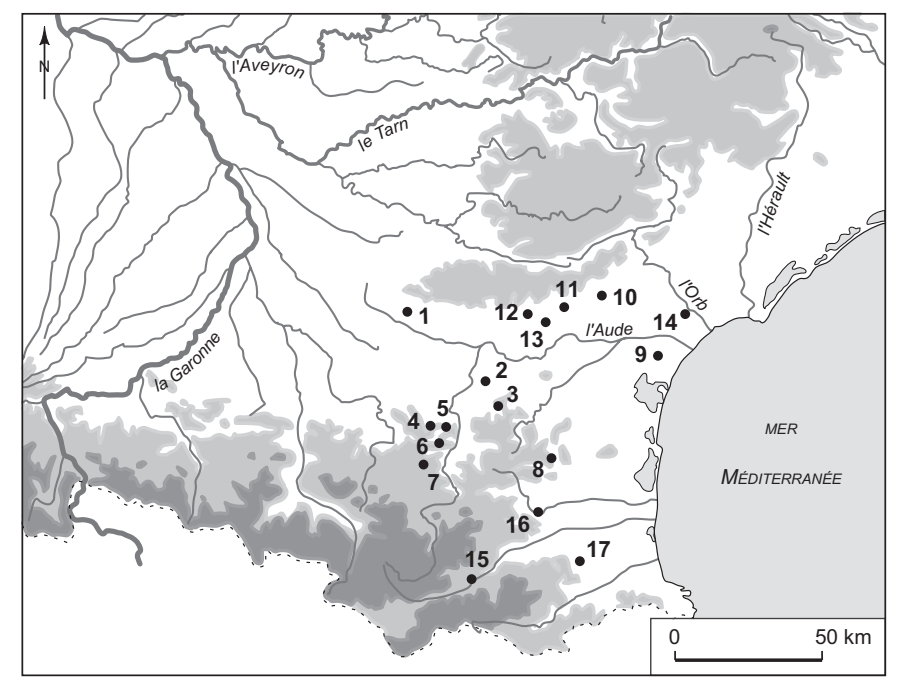

Fig. 21 - Carte de répartition des sites avec tombes à dalles lithiques du Néolithique de la zone nord-est des Pyrénées.

AUDE : 1, La Pierre à Castelnaudary ; 2, Pech dal Ome à Cavanac; 3, Labau à Ladern-sur-Lauquet ; 4, Dela Laïga à Cournanel ; 5, Las Fä̈chos à Cournanel; 6, Bordasse à Conilhac-de-laMontagne ; 7, Roca Blanca à Saint-Jean-de-Paracol; 8, La Serre à Mouthoumet; 9, Les Hauts de Narbonne à Narbonne; 10, Belbèze à Bize-Minervois.

HÉRAULT : 11, Boujas à Aigne ; 12, Najac à Siran ; 13, Coste Rouge à Beaufort; 14, la Chambre Verte à Béziers.

PYRÉNÉES-ORIENTALES : 15, Arca de Calahons à Catllar; 16, Camp del Ginebre à Caramany; 17, Arca de la Font Roja à Caixas. (DAO : J. Vaquer, CNRS).

de petites cistes enfouies, de cistes enfouies sous de petits tumulus contenus par des cercles de galets plantés, et de grands coffres (voire des chambres?) au sein de tumulus circulaires parementés. Pour ces dernières tombes il est difficile de se prononcer car les couvertures sont absentes, les possibles entrées frontales sont bouleversées ou incomplètes et, de plus, les restes osseux sont très mal conservés et les tombes ont probablement été réutilisées, peut-être à plusieurs reprises (Vignaud, 1995). Finalement c'est dans le Minervois, à quelques kilomètres de Beaufort, que l'on peut trouver d'autres tombes semblables à celle de Coste Rouge.

La première est celle de Boujas à Aigne dans l'Hérault, qui a été qualifiée de ciste incluse dans un tertre circulaire (Taffanel et al., 1975). On remarque cependant que cette tombe est, comme celle de Coste Rouge, allongée, à deux dalles latérales de chaque côté, avec une fermeture engagée qui se compose de deux plaques jointives placées sur le petit côté ouest. L'absence de couverture ne permet pas d'affirmer qu'il s'agit d'une chambre, mais cela semble très probable étant donné l'inclinaison des dalles engagées 
et les similitudes de forme et de dimensions avec la tombe de Coste Rouge. Les autres tombes qui pourraient être des chambres sont les quatre exemplaires qualifiés de coffres du site de Najac à Siran dans l'Hérault (Mahieu, 1992). Bien qu'elles n'aient été que partiellement fouillées, ce qui ne permet pas de savoir si elles ont été bâties dans des fosses ou au sein de tumulus arasés, il faut relever qu'il s'agit de grandes tombes avec des chevets monolithiques massifs, des côtés faits de plusieurs dalles et de probables fermetures engagées constituées de petites dalles fortement inclinées vers l'intérieur. Comme nous avons pu nous en rendre compte lors d'une visite du site, ces tombes sont identiques à celle de Coste Rouge et font même penser à des dolmens simples, comme cela a été envisagé dans un premier temps en raison de leur grande taille et de la présence des restes de trois, voire quatre sujets inhumés successivement dans le monument 2 (Mahieu, 1992, p. 142).

La révision du mobilier des quatre tombes de Najac apporte d'autres précisions intéressantes. Si l'attribution au Chasséen proposée par E. Mahieu n'est pas remise en cause, on est en mesure aujourd'hui de préciser qu'il ne s'agit pas de Chasséen final comme à Coste Rouge mais d'une étape ancienne du Chasséen. Le style des tessons de poteries trouvés dans la tombe 1 et dans la tombe 3 est tout à fait semblable au style dit de Berriac les Plots qui est daté de la seconde moitié du Ve millénaire avant notre ère et qui se retrouve sur plusieurs sites de l'Hérault et de l'Aude (Vaquer, 1991 ; Vaquer, Jédikian, 2003). On peut faire la même remarque au sujet de l'industrie lithique des tombes 2 et 4, qui est en silex local ou en silex bédoulien du Vaucluse non chauffé. Ce lot de pièces comporte des armatures de flèches réalisées sur éclat par des troncatures en double biseau selon une tradition fréquente à la fin du Néolithique ancien et au début du Néolithique moyen.

Sur la foi de ces indications, il ne paraît pas possible d'accorder aux tombes en chambre une grande valeur en tant que type de transition entre les petites tombes en ciste ou en coffre du Néolithique moyen et les premiers dolmens du Néolithique final. Selon toute probabilité ce type à fermeture frontale qui peut se présenter, soit au fond d'une fosse (Coste Rouge), soit inclus dans un tumulus sans couloir (Boujas et peut-être Camp del Ginebre), existe déjà dès le Chasséen le plus ancien, c'est-à-dire dans la seconde moitié du V $\mathrm{V}^{\mathrm{e}}$ millénaire (Najac), à la fin du Chasséen ancien, soit peu avant 4000 av. J.-C. (Camp del Ginebre) et tout à fait à la fin du Chasséen, peu avant 3500 av. J.-C. (Coste Rouge). Pendant cette longue durée, ce type coexiste avec un grand nombre d'autres types de tombes (en grotte, en fosse) réuti- lisant des structures d'habitat, ou dans d'autres monuments en dalles, enfouis ou sous tertre. Cette diversité de types de tombes se double même d'une diversité de mode de traitement des cadavres, comme le révèle le secteur de la vallée de l'Agly où l'on observe à la fin du IV IV $^{\mathrm{e}}$ millénaire plusieurs pratiques fort différentes. Dans la Cauna de Belesta, des dépôts de corps se trouvaient à même le sol au fond de la grotte et dans la nécropole de Camp del Ginebre, des inhumations en cistes, des incinérations en enclos bustum et des incinérations avec dépôt secondaire en loculus sont attestées au cours d'une même phase de transition entre le Montbolo et le Chasséen. On peut en conclure que les pratiques, comme les architectures funéraires, traduisent des différences sociales plutôt que les phases d'un processus évolutif se déroulant de façon homogène sur l'ensemble des Pyrénées de l'est. Dans ce contexte probablement très hiérarchisé, les tombes en chambre, comme celle de Coste Rouge, figurent parmi les plus élaborées et sans doute les plus visibles et les plus durables, si l'on se fie à l'existence de traces de tumulus ou aux cas de réutilisation.

Si l'on admet que la tombe de Coste Rouge est bien celle d'un individu de rang supérieur, le fait qu'il s'agit d'un enfant soulève d'autres questions. C'est manifestement une sépulture élaborée, avec un espace funéraire de grandes dimensions qui paraît disproportionné par rapport à la taille du sujet et qui dénote un investissement important et sans doute collectif des personnes qui ont réalisé sa construction. Le mobilier, sans être spectaculaire, est tout de même abondant par rapport aux autres tombes chasséennes connues dans la région et confirme la possibilité d'un statut social élevé de cet enfant. La documentation concernant les tombes de cette classe d'âge dans le Chasséen récent est trop lacunaire pour que l'on puisse envisager des comparaisons pertinentes. Si l'on se tourne vers la Catalogne, beaucoup mieux documentée, on constate que les tombes d'enfants, sans être les plus riches, sont parfois assez bien pourvues en mobilier, notamment en éléments de parure et en outils en os ou en lamelles de silex non utilisées. Ces faits correspondent bien à ce qui peut-être observé à Coste Rouge. Pour prendre un exemple probant, on peut citer la tombe CG 29 de Camí de Can Grau qui est celle d'un enfant de 9 ans accompagné de quatre poinçons, deux lamelles de silex, une plaquette en os et des parures faites de perles en callaïs et en os : les offrandes funéraires sont pratiquement les mêmes, hormis pour les types de parure et les deux armatures de flèches. Ces dernières pièces sont en général réservées aux adultes masculins dans les ensembles catalans (Pou i Calvet et al., 1996), mais on connaît tout de même quelques exceptions, 
comme celle associée à un enfant de 6-7 ans dans la tombe CG 6 de la même nécropole. Finalement, le caractère le plus original de la tombe de Coste Rouge tient à la présence du dépôt d'os d'animaux qui peut représenter un ensemble d'amulettes ou l'évocation symbolique d'un bestiaire d'accompagnement avec de claires connotations liées à l'élevage et à la chasse. Le sujet étant un enfant, cela pourrait signifier que la fonction socio-économique était fixée dès l'enfance et était censée se perpétuer au-delà de la mort.

\section{Remerciements}

La fouille de la tombe de Coste Rouge a été réalisée à la demande du Service régional de l'archéologie du Languedoc-Roussillon, sous la forme d'une opération de sauvetage urgent (autorisation $n^{\circ} 109 / 2001$ ) dont la maîtrise d'œuvre a été confiée à l'association « Archéologie en Terre d'Aude » qui a mobilisé plusieurs partenaires :

- le Centre d'anthropologie, UMR 8555, CNRS-EHESSUniversité Paul-Sabatier de Toulouse (délégation de J. Vaquer, directeur de recherche CNRS et M. Gandelin, étudiante doctorante) ;
- le Laboratoire d'anthropologie des populations du passé (PACEA) UMR 5199, CNRS-Université Bordeaux-I (délégation de H. Duday, directeur de recherche, S. Hérouin, ingénieur, L. de Souris et S. Jabar, étudiants doctorants) ;

- le Conseil général de l'Hérault (participation au financement du fonctionnement) ;

- un groupe de bénévoles du Centre de recherche et de documentation du Minervois d'Olonzac (J. Granier, S. Durand, M. Durand).

L'opération a bénéficié du concours de R. Marsac, agent de valorisation du patrimoine à l'association «Archéologie en Terre d'Aude » et du soutien et de l'aide du propriétaire M. Durand qui a accepté de retarder la replantation de la vigne, nous a prêté du matériel et pris à sa charge les frais de terrassement et de remise en état du terrain; nous lui adressons nos plus vifs remerciements. Nous remercions F. Briois et S. Philibert, pour leurs conseils et expertises au sujet des pièces lithiques, et $\mathrm{P}$. Marinval, pour la détermination des carporestes. L'ensemble de l'opération a fait l'objet d'un reportage documentaire filmé par S. Kowalczyk de l'entreprise Sprintvidéo. 


\section{BIBLIOGRAPHIE}

\section{BARGE $\mathbf{H}$.}

1982 : Les Parures du Néolithique ancien au début de l'âge des Métaux en Languedoc, Paris, éd. du CNRS, 396 p., 134 fig., 6 pl.

\section{BERNABó Brea M., GHiretTi A.,} Polglase C., Visconti V.

1990: «I siti neolitici lungo il torrente Cinghio (Parma) », Prehistoria alpina, 24, p. 103-164.

\section{BINDER D.}

1984: «Systèmes de débitage laminaire par pression: exemples provençaux ", in Préhistoire de la pierre taillé-2-Économie du débitage laminaire, III ${ }^{e}$ Table ronde de technologie lithique, Meudon-Bellevue, oct. 1982, Paris CREP, p. 71-84.

1991 : «Facteurs de variabilité des outillages lithiques chasséens dans le sud-est de la France ", in BEECHING A. ET AL. (DIR.), Identité du Chasséen, Actes du colloque international de Nemours 1989, Nemours, APRAIF (coll. Mémoires du Musée de la Préhistoire d'Île-de-France, 4), p. 261272.

\section{BRIOIS F.}

1997: Les Industries lithiques en Languedoc méditerranéen (6000-2000 av.J.-C.), Thèse multigraphiée, Toulouse, EHESS, 565 p., 156 fig.

\section{CAMPS-FABRER H.}

1993: «Le rôle de l'os dans les activités de l'homme néolithique et de l'âge des Métaux ", in Le Néolithique au quotidien, Actes du XVI colloque interrégional sur le Néolithique, Paris, nov. 1989, Paris, Maison des sciences de l'homme (coll. Document d'archéologie française, 39), p. 152-176.

\section{CASTANY J.}

1990 : «L'estació neolítica sepulcral de la Costa dels Garrics del Caballol (Pinell, Solsonès)", in Tribuna d'arqueologia, 1989-1990, Barcelona, Departament de la Cultura de la Generalitat de Catalunya, p. 53-64.

1992: «Estructures funeraries dels megalits neolítics del Solsonès ", in Estat de la investigació sobre el Neolític a Catalunya, 9 Col.loqui internacional de Puigcerdà, 1991, Andorra, Institut d'Estudis CeretansServei d'Arquelogia d'Andorra, p. 249253.

\section{Cazalis de Fondouce $P$.}

1900 : «L'Hérault aux temps préhistoriques », in Géographie générale du département de
l'Hérault, Montpellier, Société languedocienne de géographie, 195 p.

Chantret F., Guilaine J., Guillemaut A. 1970 : «Analyses de quelques perles méridionales en callaïs ", Bulletin de la Société préhistorique française, 67, crsm 7, p. 216-219.

Claustre F., ZAmmit J., Blaize Y. ET AL. 1993 : La Cauna de Bélesta, une tombe collective il y a 6000 ans, Toulouse, Centre d'anthropologie des sociétés rurales, 286 p., 173 fig., 29 photos, 27 tabl.

\section{Costantini G.}

1984 : «Le Néolithique et le Chalcolithique des Grands Causses ", Gallia Préhistoire, 27, 1, p. 121-210.

\section{CoURTIN J.}

1974: Le Néolithique de la Provence, Paris, Klincksieck (coll. Mémoires de la Société préhistorique française, 11), 359 p., 126 fig., 31 pl.

\section{Cremonesi G., Grifoni R., RADi G.,} Tozzi C., Nicolis F.

1998: «L'Italie centrale», in GUILAINE J. (DIR.), Atlas du Néolithique européen. L'Europe occidentale, Liège, Université de Liège (coll. ERAUL, 46, vol. 2A), p. 165-231.

Cruells W., Castells J., Molist M.

1992 : «Una necrópolis de "cambres amb tumul complex" del IV milleni a la Catalunya interior ", in Estat de la investigació sobre el Neolític a Catalunya, 9 Col. loqui internacional de Puigcerdà, Andorra, Institut d'Estudis Ceretans-Servei d'Arqueologia d'Andorra, p. 244-248.

\section{Cura Morera M.}

1992 : «Noves apportacions al megalitisme català. Revisio de les sepultures del Solsonià amb l'aparicio de les primeres cambres neolítiques », in Estat de la investigació sobre el Neolític a Catalunya, 9 Col. loqui internacional de Puigcerdà, Andorra, Institut d'Estudis Ceretans-Servei d'Arqueologia d'Andorra, p. 262-264.

FAGES A.

1923: "Sépulture de Lapierre près de Castelnaudary (Aude)", Bulletin de la Société d'études scientifiques de l'Aude, XXIII, p. 89-90.

1930: «Fouilles d'une tombe à dalles de l'époque néolithique », Bulletin de la Société d'études scientifiques de l'Aude, XXXIV, p. 103-106.

\section{GASSIN B.}

1996 : Évolution socio-économiquedansle Chasséen de la grotte de l'Église supérieure (Var), Paris, CNRS Éditions (coll. Monographies du CRA, 17), 326 p.

\section{Gibaja BaO J.-F., Clemente Conte I.}

1996 : «Analísis funcional del material litico en las sepulturas de la Bóvila Madurell (Sant Quirze del Vallès, Barcelona)", in Actes del $1^{\text {er }}$ congrès del Neolític a la Peninsula Ibèrica, Gava-Bellaterra, 27-29 marc 1995, vol. 1, Gavà, Museu de Gavà (coll. Rubricatum, 1), p. 183-189.

GUILAINE J.

1962 : «Sépultures néolithiques dans le sud de la France », Zephyrus, XIII, p. 17-29.

1967: La Civilisation du vase campaniforme dans les Pyrénées françaises, Carcassonne, éd. du Laboratoire de palethnologie de Carcassonne, 240 p., 52 fig., 9 pl.

1996 : «Proto-mégalithisme, rites funéraires et mobiliers de prestige néolithiques en Méditerranée occidentale ", in Homenaje al Profesor Manuel Fernández Miranda, t. 1, Madrid, Universidad complutense (coll. Complutum, extra 6), p. 123-140.

\section{Guilaine J., Muñoz A. M.}

1964 : « La civilisation catalane des "Sepulcros de fosa” et les sépultures néolithiques du sud de la France ", Revue d'Études ligures, XXX, 1-4, p. 6-30.

\section{Gutherz X., Hugues C.}

1980 : «La culture du Vase campaniforme dans le département du Gard ", Bulletin de l'École antique de Nîmes, 1980, p. 5-26.

Jeunesse C., Pétrequin P., Piningre J.-F. 1998 : "L'est de la France ", in GuILAINE J. (DIR.), Atlas du Néolithique européen. L'Europe occidentale, Liège, Université de Liège (coll. ERAUL, 46, vol. 2A), p. 501-584.

\section{LLOVERA X.}

1986 : « La Feixa del Moro (Juberri, Andorra) i el Neolític mig-recent a Andorra ", in Tribuna d'arqueologia, 1985-1986, Barcelona, Departament de la Cultura de la Generalitat de Catalunya, p. 14-24.

\section{Llovera X., Ganturri P.}

1988 : «Du Néolithique moyen II au Néolithique final au nord-ouest des Alpes ", in Actes $d u$ $12^{e}$ colloque interrégional sur le Néolithique de l'est de la France, Lons-le-Saunier, oct. 1985, Lons-le-Saunier, Musée de Lons-le-Saunier, Cercle Girardot, p. 243-250. 
LOUiS M., TAFFanel O., TAFFAnEl J.

1958: Le Premier âge du Fer languedocien -IILes Nécropoles à incinération, BordigheraMontpellier (coll. Monographie de l'Institut d'études ligures), $264 \mathrm{p}$.

\section{MAHIEU E.}

1992: «La nécropole de Najac à Siran (Hérault) », Gallia Préhistoire, 34, p. 141-169.

\section{MARIËN M., ULRIX-ClOSSET M.}

1985 : Du Néolithique à l'âge du Bronze dans le sud-est de l'Espagne, Bruxelles, Musées royaux d'Art et d'Histoire (coll. Siret), 153 p., 97 fig.

MaRTí I Rossel M., POU I CALVET R., CARLUS I MARTIN X. (DIR.)

1997: La Necròpolis del Neolític mitjà, $i$ les restes romanes de Cami de Can Grau, La Roca del Vallès, Vallès occidental, Barcelona, Departament de la Cultura de la Generalitat de Catalunya (coll. Excavacions arqueológiques a Catalunya, 14), p. 37-197, 85 fig., XIII pl.

\section{MARTIN R.}

1957 : Lehrbuch der Anthropologie in systematischer Darstellung, $3^{\mathrm{e}}$ éd. revue et corrigée par K. Saller, Stuttgart, Fischer Verlag, 2999 p., 1253 fig.

Martín Cólliga A., Villalba Ibañez M. J. 1999: «Le Néolithique moyen de la Catalogne ", in VAQUER J. (DIR.), Le Néolithique du nord-ouest méditerranéen, Actes du XXIV congrès préhistorique de France, Carcassonne, 1994, Paris, Société préhistorique française, $296 \mathrm{p}$.

\section{MARTINEZ MORENO J.}

1997 : «Restes òssies i indústria òssia de la necròpolis del Camí de Can Grau ", in MARTí I ROSSEL M. ETAL. (DIR.), La Necròpolis del Neolític mitjà, i les restes romanes del Cami de Can Grau, La Roca del Vallès, Vallès occidental, Barcelona, Departament de la Cultura de la Generalitat de Catalunya (coll. Excavacions arqueológiques a Catalunya, 14), p. 141-152.

\section{MIQUEL J.}

1895 : «Essai sur l'arrondissement de SaintPons ", Bulletin de la Société languedocienne de géographie, XVII, 1, p. 329-330.

\section{MOINAT P.}

1998: "Les cistes de type Chamblandes, rites funéraires en Suisse occidentale», in Guilaine J. (DIR.), Sépultures d'Occident et genèses des mégalithismes, Paris, éd. Errance, p. 129-143.

Molist M., Cruells W, Castells J. 1987: «L'àrea megalitica de Tavertet
(Osona) », in "Dossier megalitisme : arquitectura i societat", Cota Zero, 3, p. $55-68$.

Moorree G. F. A., FANNing A., HUNT E. E. 1963a : "Age variation of formation stages for ten permanent teeth", Journal of Dental Research, 42, p. 1490-1502.

1963b : «Formation and resorption of three deciduous teeth in children ", American Journal of Physical Anthropology, 21, p. 205213.

\section{MUÑoz AMibilia A. M.}

1965: La Cultura neolítica catalana de los "Sepulcros de fosa", Barcelona, Universidad de Barcelona (coll. Publicacions eventuales de Pyrenae, 9), 417 p., 109 fig., XL pl.

Pou i Galvet R., Martí I Rossel M., BORDAS TISSIER A.-B., DIAZ ORTELlS J., Mártin Cólliga A.

1996: "La cultura de los Sepulcros de fosa en el Vallès/Los yacimientos de la Bóvila Madurell y Camí de Can Grau (Sant Quirze del Vallès y La Roca del Vallès, Barcelona) ", in Actes del $1^{e r}$ congrès del Neolític a la Peninsula Ibèrica, GavàBellaterra, 27-29 marc 1995, vol. 2, Gavà, Museu de Gavà (coll. Rubricatum, 1), p. 519-526.

\section{SAINTOT S.}

1998: "Les armatures de flèches en silex de Chalain et de Clairvaux", Gallia Préhistoire, 40, p. 204-247.

\section{SAUZADE G.}

1983 : Les Sépultures du Vaucluse, du Néolithique à l'âge du Bronze, Paris, éd. du Laboratoire de paléontologie humaine et de préhistoire (coll. Études quaternaires, 6), 253 p., 97 fig., $20 \mathrm{pl}$

\section{SAUZADE G., Grenet M.}

1996 : Saint-Jean-du-Désert, les tombes jumelles préhistoriques, Brochure de la DDE des Bouches-du-Rhône, Ville de Marseille, 8 p., 10 fig.

\section{SÉNÉPART I., SIDÉRA I.}

1991: «Une culture chasséenne pour les matières dures animales?", in BEECHING A. ET AL. (DIR.), Identité du Chasséen, Actes du colloque international de Nemours, 1989, Nemours, APRAIF (coll. Mémoires du Musée de Préhistoire d'Îlede-France, 4), p. 299-312.

\section{SIDÉRA I.}

2000: «Animaux domestiques, bêtes sauvages et objets en matières animales du Rubané au Michelsberg », Gallia Préhistoire, 42, p. 107-194.
TAFFanel O., TAFfanel J., AMbert P.

1975 : «La ciste de Boujas (Aigne, Hérault) ", Bulletin de la Société d'études scientifiques de l'Aude, LXXV, p. 113-119.

TAFFANEL O., TAFFANEL J., JANIN T.

1998: La Nécropole du Moulin à Mailhac (Aude), Lattes, Monique Mergoil (coll. Monographie d'archéologie méditerranéenne, 2), 393 p., 478 fig.

\section{TARRUS J.}

1987: «El megalithisme de l'Alt Empordà (Girona) : els constructors de dolmens entre el Neolític mitjà i el Calcolitic a l'Albera, Serra de Roda i Cap de Creus ", in « Dossier megalitisme : arquitectura i societat », Cota Zero, 3, p. 36-54.

\section{UERPMANN M}

1977 : « Kulturelle aspekte der abschlagtechnologie im Neolithikum der Schweiz", Archäologisches Korrespondenzblatt, 7, 2, p. 95-99.

\section{VAQUER J.}

1991 : «Aspects du Chasséen en Languedoc occidental ", in BEECHINGA. ETAL. (DIR.), Identité du Chasséen, Actes du colloque international de Nemours 1989, Nemours, APRAIF (coll. Mémoires du Musée de la Préhistoire d'Île-de-France, 4), p. 27-37.

1998: «Les sépultures du Néolithique moyen en France méditerranéenne", in Guilaine J. (DIR.), Sépultures d'Occident et genèses des mégalithismes, Paris, éd. Errance, p. 167-186.

VAQUER J., JÉDIKIAN G.

2003: «La Salle, Carcassonne (Aude). Un habitat de plein air du groupe de Bize ", Bulletin de la Société préhistorique française, 100 , 2, p. 323-351.

\section{VIGNAUD A.}

1995: «L'occupation néolithique dans la cuvette de Caramany, moyenne vallée de l'Agly (Pyrénées-Orientales) », in Cultures $i$ medi : de la Prehistoria a l'Edat mitjana: 20 anys d'arqueologia pirinenca: homenatge al Professor Jean Guilaine, 10 Col.loqui internacional d'arqueologia de Puigcerdà, 10-12 nov. 1994, Puigcerdà, Institut d'Estudis Ceretans, p. 291-297.

2000 : «Narbonne, Les Hauts de Narbonne RN 213 », Bilan scientifique régional du Languedoc-Roussillon, 2000, p. 56-57.

\section{VILASECA S.}

1973 : Reus y su entorno en la Prehistoria, Reus, Associación de estudios reusenses, 2 vol. 284 p., 174 fig., 144 photos. 